\author{
RESEARCH ARTICLE \\ 10.1029/2018JC014865 \\ Key Points: \\ - Field observations confirm previous \\ wave-vegetation interaction studies \\ and support the existing theoretical \\ models for wave propagation \\ - Mendez and Losada's formulation \\ satisfactorily predicts wave \\ attenuation by vegetation under \\ tidal currents up to at least $0.2 \mathrm{~m} / \mathrm{s}$ \\ - New field-based formulations \\ demonstrate that 100-year \\ recurrence interval waves are \\ attenuated by $70 \%$ at $250 \mathrm{~m}$ from the \\ marsh edge
}

Supporting Information:

- Supporting Information S1

Correspondence to:

J. L. Garzon,

jgarzon3@gmu.edu

Citation:

Garzon, J. L., Maza, M., Ferreira, C. M., Lara, J. L., \& Losada, I. J. (2019). Wave attenuation by Spartina saltmarshes in the Chesapeake Bay under storm surge conditions. Journal of Geophysical

Research: Oceans, 124, 5220-5243.

https://doi.org/10.1029/2018JC014865

Received 13 DEC 2018

Accepted 18 JUN 2019

Accepted article online 26 JUN 2019

Published online 28 JUL 2019

(C)2019. American Geophysical Union. All Rights Reserved.

\section{Wave Attenuation by Spartina Saltmarshes in the Chesapeake Bay Under Storm Surge Conditions}

\author{
Juan L. Garzon' (D, M. Maza' (D, C. M. Ferreira' ${ }^{1}$ (D), J. L. Lara' ${ }^{2}$ and I. J. Losada' \\ ${ }^{1}$ Department of Civil, Environmental and Infrastructure Engineering, George Mason University, Fairfax, VA, USA, \\ ${ }^{2}$ Environmental Hydraulics Institute (IHCantabria), Universidad de Cantabria, Santander, Spain
}

\begin{abstract}
This study investigates the capacity of a Spartina alterniflora meadow to attenuate waves during storm events based on field observations in the Chesapeake Bay. These observations reveal that environmental conditions including the ratio between water depth and plant height $\left(h_{r}\right)$, the ratio between wave height $\left(H_{S}\right)$ and water depth, and current directions impact the wave height decay. Further, we present empirical representations of the bulk drag coefficient $\left(C_{d}\right)$ as a function of the Keulegan-Carpenter (KC) and Reynolds (Re) numbers, and the $h_{r}$ ratio. When applying the distinction between current directions, this representation exhibits better agreement when using the $\operatorname{Re}\left(\rho^{2}=54 \%\right)$ and $h_{r}\left(\rho^{2}=77 \%\right)$ than with the $\mathrm{KC}\left(\rho^{2}=39 \%\right)$. Furthermore, we show that the representation of $C_{d}$ can be improved by using a $h_{r}$-based modified Re and $\mathrm{KC}$ formulation, yielding correlations of $76 \%$ (modified $\mathrm{Re}$ ) and $78 \%$ (modified KC). The proposed expressions are validated during another storm and predicted $H_{S}$ computed within the marsh results in a root-mean-square error of $0.014 \mathrm{~m}$, overestimating the largest $H_{S}(0.22 \mathrm{~m})$ by $18 \%$. Finally, these expressions are applied to several hypothetical sea conditions. Under similar vegetation characteristics, $H_{S}$ of 1.55 and $0.8 \mathrm{~m}$ (close to a 10,000- and 100-year recurrence interval storm) are attenuated by $50 \%$ and $70 \%$, respectively, at $250 \mathrm{~m}$ from the marsh edge. This study provides evidence that validates the saltmarsh wave attenuation capacity during storms, quantifies this attenuation, and supports the transferability of the existing formulas in the literature across similar coastal marshes.
\end{abstract}

\section{Introduction}

The use of green infrastructure to protect coastal communities has gained popularity during the last decade, especially under the threat of rising sea levels and changes in global and regional climate patterns. Natural coastal areas, such as saltmarshes, can attenuate the impact of coastal storms on hard structural flood defenses, reducing their building and maintenance cost (Sutton-Grier et al., 2015; Vuik et al., 2016). Several studies have already demonstrated the ability of these natural solutions to efficiently attenuate storm surge, wave energy, and current velocities (Costanza et al., 2008; Garzon et al., 2019; Glass et al., 2017; Maza et al., 2015; Mendez \& Losada, 2004; Möller et al., 2014; Möller \& Spencer, 2002; Nepf, 2004; Resio \& Westerink, 2008). Furthermore, these ecosystems continuously provide (not only during storm events) many cobenefits in addition to wave protection services, including water quality improvements, sediment budget, carbon sequestration and storage, fishery habitat, and opportunities for tourism, recreation, education, and research (Barbier et al., 2011; Castagno et al., 2018; Donatelli et al., 2018; Sutton-Grier et al., 2015). Another highly important coastal protection service of these ecosystems is the capacity of accreting vertically and maintaining shallow water depths under certain sea level rise rates (D'Alpaos et al., 2011; Kirwan et al., 2010; Temmerman et al., 2013). Previous authors have reported this service (e.g.: Mudd et al., 2010; Woodroffe et al., 2016), including ecosystem adaptation to climate change (some ecosystems can build up soil at the same pace as water level rises if they have the needed sediment supply). However, the protection capacity provided by this ecosystem differs between species, and therefore, it is expected to vary across plant communities. Among different plants present in saltmarshes, two smooth cordgrass species, Spartina alterniflora and Spartina anglica, have received significant attention as a viable alternative for coastal protection. The former is the dominant plant of the intertidal zones along the Gulf and Atlantic coasts of the United States, meanwhile the latter inhabits coastal marshes in western Europe (Jackson et al., 1985). These species pioneer lower marsh areas, and thus, are exposed to frequent and direct impact of waves (Knutson et al., 1982). Several laboratory and field experiments have led to a better understanding of the coastal protection 
service provided by saltmarshes inhabited by $S$. alterniflora or $S$. anglica by exploring the interaction of these marsh species with different hydrodynamics conditions (Anderson \& Smith, 2014; R. Jadhav \& Chen, 2012; Maza et al., 2015; Yang et al., 2012). These studies determined that the hydrodynamic conditions, such as the inundation height, wave height, and period, along with plant characteristics, play a significant role in the wave energy damping capacity of a saltmarsh.

Laboratory studies have investigated the interactions between idealized saltmarshes and oscillatory flow (Anderson \& Smith, 2014; Bouma et al., 2005; Ozeren et al., 2014; Wu \& Cox, 2015) providing critical insights on the role of the effects of hydrodynamic conditions on wave energy dissipation by vegetation. However, the representation of the idealized vegetation as cylindrical elements might not accurately represent the geometrical and mechanical properties of the vegetation stems (Lara et al., 2016). Moreover, other essential characteristics representing natural S. alterniflora or S. anglica communities, such as the spatial distribution, the vertical variability, and their anchoring system to the ground (e.g., rhizome systems), are not properly represented in these experiments. Therefore, the application of predictive models for wave attenuation across saltmarshes derived from mimic-grass laboratory observations might provide unrealistic values (Lara et al., 2016). Ozeren et al. (2014) also pointed out that an array of cylinders may not be sufficient to properly reproduce the wave height dissipation induced by real plants. In an effort to bridge this gap, they transferred S. alterniflora from the Gulf of Mexico and evaluated the attenuation capacity of this species in a laboratory experiment. Maza et al. (2015) successfully grew S. anglica and conducted a laboratory experiment combining waves and currents. While these studies have had a considerable impact on the current state of the art, hydraulic flumes or tanks pose several limitations. For instance, flume operability might limit the number of cases of flow conditions assessed, and therefore, they cannot completely reproduce water level and current fluctuations resulting from astronomical and storm tides. Moreover, the actual spatial variability of plant characteristics adds an extra complexity to the wave attenuation processes in real saltmarshes.

Field experiments documenting wave attenuation across saltmarshes inhabited by $S$. alterniflora and $S$. anglica have been conducted at temperate regions around the world (Jadhav et al., 2013; I. Möller, 2006; Yang et al., 2012). Nevertheless, only a few have developed and validated a model that can be used for predicting the wave height evolution within marshes. Knutson et al. (1982) presented an empirical equation to estimate the wave transmission over a marsh transect and validated their model against observations collected in saltmarshes of the Chesapeake Bay. Thirty years later, Yang et al. (2012) included a new coefficient into the Knutson et al. (1982) model to consider the effect of plants and bottom friction. Although this model was successfully validated at a saltmarsh in the Yangtze Estuary (China), it failed to predict wave height observations reported by Knutson et al. (1982). On the other hand, Jadhav and Chen (2012) proposed a spectral drag coefficient formulation that assumes that the drag coefficient is dependent on frequency, differently from what other authors have proposed (Mendez \& Losada, 2004). However, this formulation has been verified only using the same data set on which it is based. Furthermore, the frequency dependency of this formulation adds an additional constraint, resulting in a highly complex formulation for quantifying the coastal protection services provided by reducing the incoming wave energy.

On the other hand, saltmarshes are located in intertidal zones that can be significantly impacted by currents but much less information is available documenting the complex interaction between vegetation, waves, and underlying currents simultaneously (Maza et al., 2015). Previous studies, mainly based on physical experiments, have demonstrated that currents might play an important role on the attenuation capacity of the vegetation (Hu et al., 2014; Li \& Yan, 2007; Losada et al., 2016; Maza et al., 2015; Paul et al., 2012). For instance, Paul et al. (2012) observed that tidal currents, flowing in the same direction as waves, strongly reduced the wave-attenuating capacity of seagrass mimics. Similarly, Maza et al. (2015) observed higher wave damping when the currents opposed wave propagation than the no current case and lower wave attenuation with currents acting in the same direction as the waves. Also, the wave attenuation was larger with waves travelling obliquely to currents than collinear currents. On the other hand, Li and Yan (2007) reported that following currents increased the attenuation. Hu et al. (2014) stated that these discrepancies might be caused by differences in the ratio between the imposed current velocity and the amplitude of horizontal orbital velocity. Moreover, Hu et al. (2014) and Losada et al. (2016) used different approaches to derive analytical formulations for vegetation-induced damping under waves and currents. While the findings of these studies represent an extraordinary advance to better understand the wave attenuation under the combined effect of waves and currents, the transferability of their outcomes to field experiments is 
challenging due to highly varied conditions observed in a real marsh during a storm event. Topography and meadow patches influence the flow within a marsh platform, and therefore, isolating the effects of currents might result in an extremely complex task. In fact, only one experiment, Gaylord et al. (2003) have evaluated the effect of alongshore currents using field measurements and it demonstrated that the currents decrease the wave attenuation induced by the vegetation.

This study investigates the vegetation-induced wave attenuation along a cross-shore transect at a natural preserve area of the Chesapeake Bay based on field measurements during storm conditions. The study presents a new field-based estimation and validation of the bulk drag coefficient $\left(C_{d}\right)$ as a function of KeuleganCarpenter (KC) and Reynolds (Re) numbers for S. alterniflora. Additionally, the study evaluates wave attenuation by vegetation under the combined effect of currents and waves and under real storm conditions in the field. Moreover, while previous studies demonstrated the potential of saltmarsh ecosystems for providing coastal protection (Möller et al., 2014; Narayan et al., 2016), this study uses newly proposed and validated empirical expressions to assess the ability of these ecosystems to attenuate wave heights under a wide range of hypothetical hydrodynamic conditions and vegetation configurations.

\section{Materials and Methods}

\subsection{Study Area}

The field campaigns were conducted at a natural reserve located at the southern tip of the Delmarva Peninsula: the Eastern Shore of Virginia National Wildlife Refuge (hereafter ES), managed by the U.S. Fish and Wildlife Service. The Delmarva Peninsula, in the U.S. mid-Atlantic region, is a narrow peninsula bordered by the Chesapeake Bay on the western side and the Atlantic Ocean on the eastern side (Figures 1a and 1b). The ES site is located near the mouth of the Chesapeake Bay, where the mean tidal amplitude is $0.9 \mathrm{~m}$, at the north of Fisherman Island National Wildlife Refuge and behind an inlet created at the barrier island system. The average tidal current amplitude reported at the mouth of the bay is approximately $1 \mathrm{~m} / \mathrm{s}$ (Xiong \& Berger, 2010) and it was observed to be in phase with the water levels. Besides the currents flowing in and out of the Chesapeake Bay, the study area is influenced by a 100-m-wide channel reaching this area, the barrier island structure, and high-energy waves coming from the open ocean (Figure 1). The soil is formed by an unconsolidated organic ooze with an overlying rhizomatous layer of varying integrity (Stevenson et al., 1985).

The field deployment layout, shown in Figures 1c and 1d, was designed to explore the effects of the marsh edge along with the vegetation on the wave propagation through the marsh. The study site presented a 0.9-m cliff marsh edge and a relatively flat marsh platform with an average slope of $0.014 \%$ (between station 2, S2, and station 4, S4). The first station (S1) was located seaward the marsh edge on a no-vegetated mudflat region. The elevation of this station is NAVD88 $-0.9 \mathrm{~m}$. Station 2 was less than $4 \mathrm{~m}$ inland from the edge of the marsh with an elevation of around NAVD88 $+0.09 \mathrm{~m}$ and located $25 \mathrm{~m}$ away from the S1. Station 3 (S3) was located before the tributaries and $23 \mathrm{~m}$ away from S2. The elevation of this station was NAVD88 +0.06 $\mathrm{m}$. The last station, S4, was located behind those tributaries, $82 \mathrm{~m}$ away from S3, and its elevation was NAVD88 +0.23 m. For the calculations, the stations were assumed to lie on a straight line perpendicular to the shoreline (Figure 1), whose direction was equivalent to the wave propagation.

\subsection{Data Collection and Processing}

\subsubsection{Hydrodynamic Measurements}

Total pressure was recorded continuously at $4 \mathrm{~Hz}$ from 24 to 30 September 2015 at the monitoring stations in the study area with high-frequency pressure data loggers, Trublue 255 level. Also, a low-frequency pressure transducer, Hobo onset U20L-01, was used to record atmospheric pressure at the study site (see Paquier et al. (2016) for further details). The data loggers deployed at the marsh platform stations such as S2, S3, and S4 were alternatively wet and dry based on the tide elevation, since these sensors were emerged during the lowest part of the tidal cycles. However, data processing at each station was restricted to water depths higher than $0.4 \mathrm{~m}$ above the ground at S4 (NADV88 +0.63 m). The measured pressure data consisted of the combination of atmospheric pressure, hydrostatic pressure, and dynamic wave pressure. These components were separated and divided into synchronous 20-min bursts during the data postprocessing. Following the methodology presented by Möller and Spencer (2002), the hydrostatic pressure signal was used to compute water depth, while the dynamic pressure signal was then used to estimate the wave energy spectra for each station. 

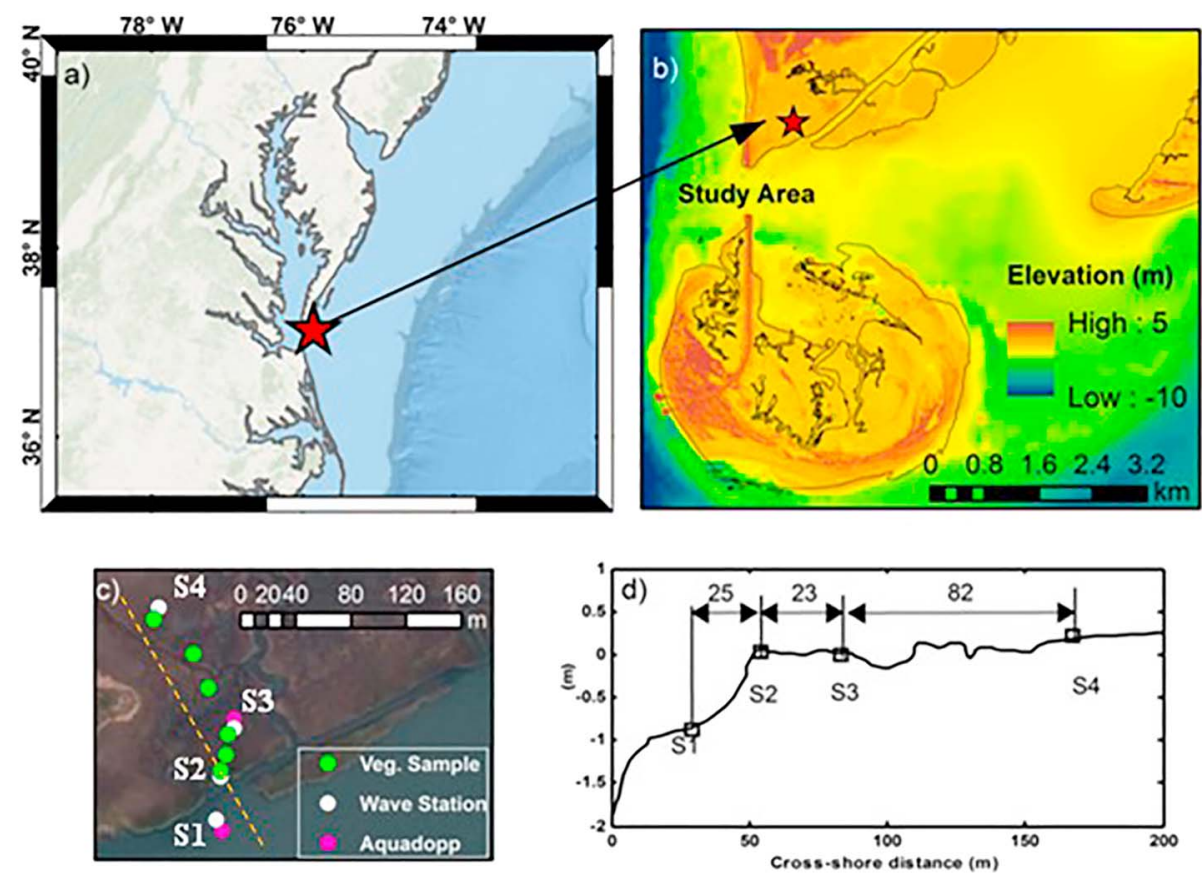

Figure 1. (a) Location of the Chesapeake Bay in the United States. (b) Location of the study area: Eastern Shore. (c) Aerial view and location of the measurement devices and the vegetation survey samples in the study area. Dashed line represents the normal transect used on the calculations. (d) Topo-bathymetric transect and location of the wave stations.

Furthermore, the pressure linear transfer function, which is a function of the hydrostatic pressure as well as the wavelength, was also included in the computations. These spectra were calculated using a fast Fourier transform considering 1,024 components and 20-min Hanning windows with 75\% overlapping in each burst. Thus, significant wave height $H_{S}$ was calculated as

$$
H_{S}=4.004 \sqrt{m_{0}}
$$

where $m_{0}$ is the variance of the one-dimensional water surface elevation spectrum $E(\sigma)$, which varied with frequency $\sigma$. Peak period $\left(T_{P}\right)$ was determined as the wave period containing the greatest energy inside the spectral window $(0.06-0.75 \mathrm{~Hz})$.

Additionally, two Aquadopps or ADCPs, Nortek $2 \mathrm{MHz}$, were deployed from 24 September to 30 October 2015. The bottom mounted Aquadopps were installed in an up-looking position and configured to measure current direction and magnitude across the water column at every $10-\mathrm{cm}$ vertical layer with a $0.1-\mathrm{m}$ blanking distance. The velocity profiles were averaged every minute and recorded every $10 \mathrm{~min}$. The instruments were located: (1) in the water, shoreward from the edge of the marsh, and (2) in the marsh platform, $6 \mathrm{~m}$ away from S3 (Figure 1c). Besides measuring current direction and magnitude, they also measured wave direction and pressure signal at $2 \mathrm{~Hz}$ in bursts of 2,400 samples every 3,600 s. Similarly, this pressure data were used to estimate wave energy spectra and consequently, significant wave height and peak period. Comparisons of wave parameters obtained from the Aquadopps and pressure data loggers (not shown here) demonstrated that $2-\mathrm{Hz}$ measurements are able to perform similarly to $4-\mathrm{Hz}$ measurements under these conditions.

According to Paul and Amos (2011), reflection and shoaling are not expected to have a significant impact on wave transformation within this planar and gentle sloping marsh platform $(\sim 1: 700)$. Other impacts on approaching waves, such as breaking, were further explored. Thornton and Guza (1982) defined the critical breaking parameter $(\gamma)$ as the ratio of $H_{\text {rms }}$ (root-mean-square wave height) and water depth, with breaking occurring for $\gamma$ varying between 0.2 and 0.6 for gentle sloping ( $<1: 100)$ beaches (Raubenheimer et al., 2001). In this study, the highest values of $\gamma(0.23)$ were observed during the high tides (see Figure $\mathrm{S} 1$ in the supporting information for more information). Furthermore, based on the analysis of daylight pictures taken every 15 min displaying the marsh edge, it can be demonstrated that there was not significant breaking over the 

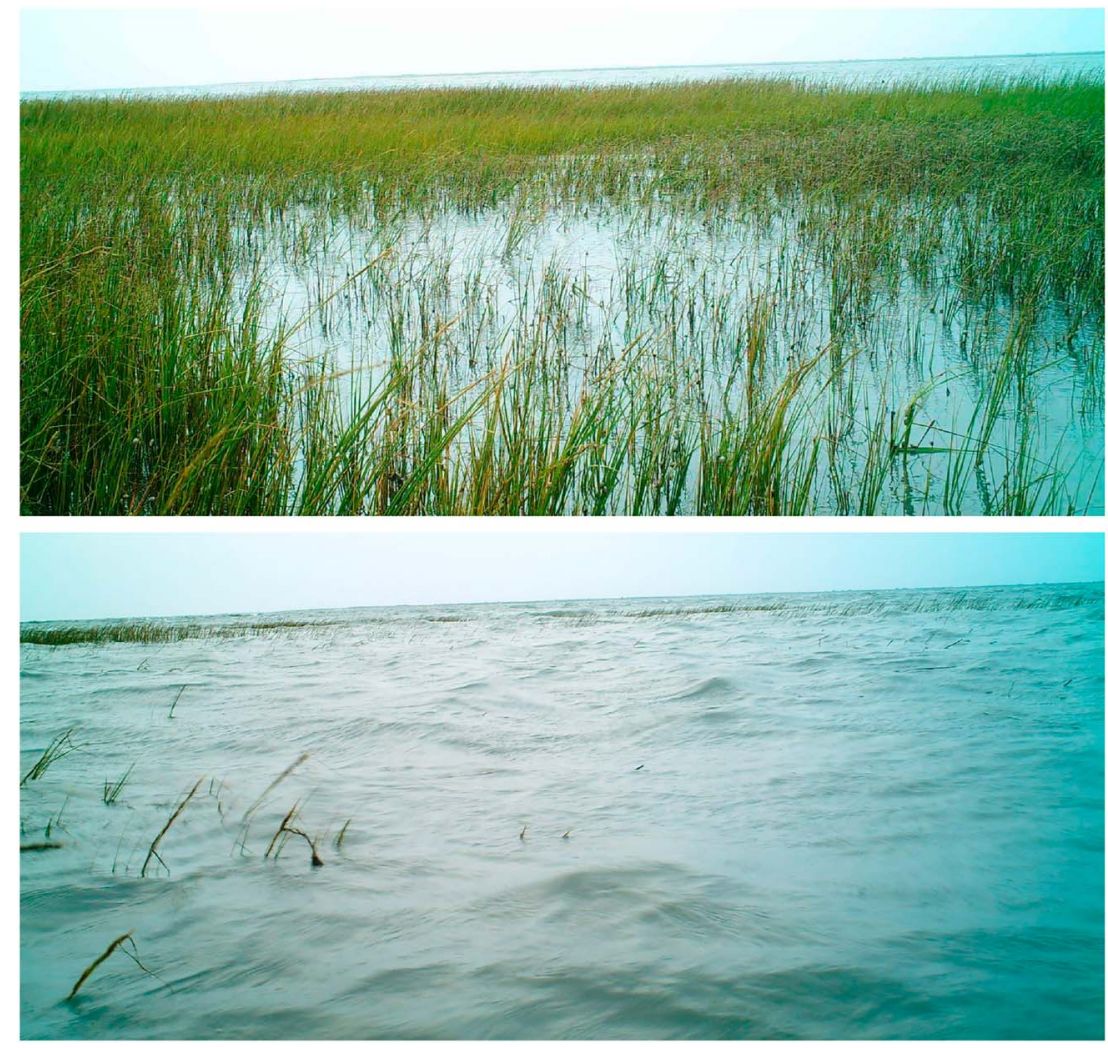

Figure 2. Marsh platform displaying station 2 (backside of the picture). Top plot shows the marsh platform under an inundation height of $0.4 \mathrm{~m}$ and the bottom plot shows the marsh during the high tide of the 26 September 2015, when the water depth was $0.9 \mathrm{~m}$ approximately.

edge. This was the place where waves were more vulnerable to breaking, since once waves propagated through the vegetation, they rapidly decreased their heights. One example of these pictures is shown Figure 2. Additionally, results from wave propagation based on XBeach simulations are provided in the supporting information. These simulations also supported the hypothesis that breaking might be neglected in this analysis.

\subsubsection{Coastal Storms}

During the instrument deployment period, two severe events impacted the study area. These events were the combination of significant spring tides and onshore gale-force winds from storms located at the mid-Atlantic region coast. Figure 3 displays wave heights, peak periods, and water levels measured at the seaward ADCP during both events. The first event lasted from 24 September to 30 September, reaching its peak on 26 September. Maximum water depths and wave heights displayed in Figure 3 reached values up to 1.8 and $0.35 \mathrm{~m}$, respectively. The second event was more energetic and lasted from 1 to 5 October. Two peaks were observed during this time: 2 and 4 October. Water depths exceeded $2 \mathrm{~m}$ and wave height reached $0.4 \mathrm{~m}$ as it is shown in Figure 3. According to the Chesapeake Bay Bridge Tunnel NOAA station located $20 \mathrm{~km}$ apart from the study area, water levels observed during second event are the seventh highest since 1975, when they started collecting measurements. Furthermore, the water-level Annual Exceedance Probability Curves reported at the Chesapeake Bay Bridge Tunnel NOAA station demonstrated that this event exhibited approximately a return period of 15 years, while the first event return period was about 2.5 years. The Chesapeake Bay Bridge Tunnel NOAA station reported maximum wind speeds of 14-16 m/s for both events (Glass et al., 2017). The pressure data loggers captured the first event in September, while the Aquadopps were able to monitor both events.

\subsubsection{Vegetation Characteristic Measurements}

Paquier et al. (2016) reported vegetation species and characteristics measured on 17 October 2015 in ES at six locations along the marsh transect, as it is displayed in Figure 1c. They noticed that the dominant specie was 

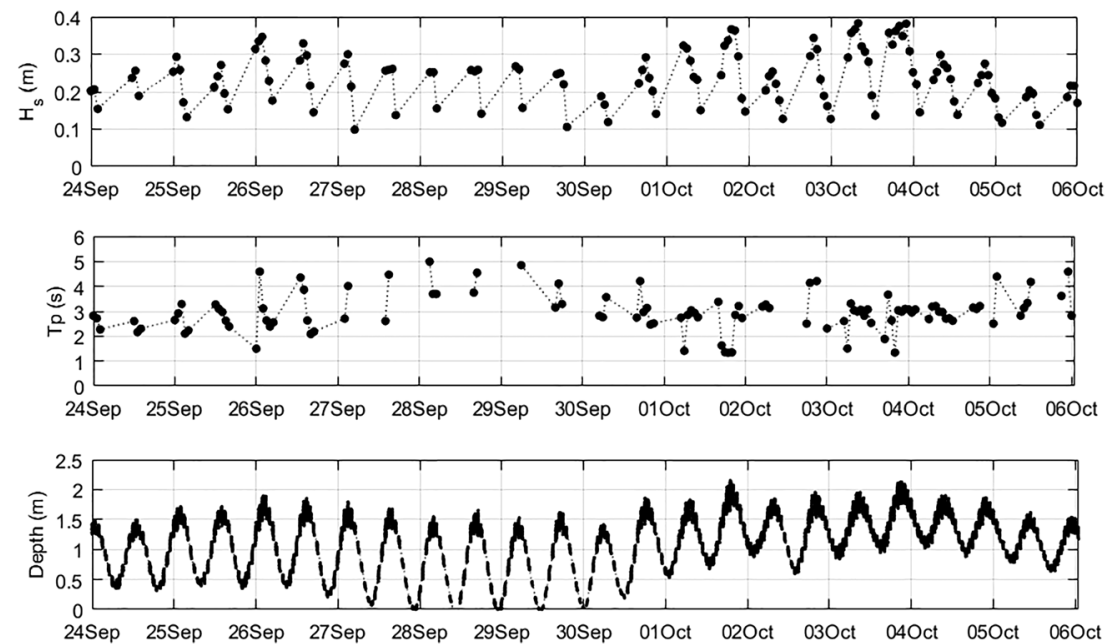

Figure 3. Top panel displays the significant wave heights, middle panel shows the peak periods, and bottom panel depicts the water depths measured at the seaward Aquadopp during the September and October 2015 events.

S. alterniflora, as it was observed in previous studies conducted in the Chesapeake Bay region (Knutson et al., 1982). The biometric measurements were carried out in a $25 \times 25$-cm quadrant (three samples per station) and consisted of geographical locations, five plant heights, five stem diameters, and total stem number. The stem densities varied between 270 and 425 stems per $\mathrm{m}^{2}$ between S2 and S4 with an average of 344 per $\mathrm{m}^{2}$ and a standard deviation of 80 stem per $\mathrm{m}^{2}$ (see Figure 4). The tallest stems were observed close to the shoreline (more than $80 \mathrm{~cm}$ ), generally decreasing at the end of the marsh, except in the vicinity of the main channel after S3. The average and the standard deviation were 71 and $22 \mathrm{~cm}$, respectively. Stem diameters varied between 4 and $7 \mathrm{~mm}$ with an average of $5 \mathrm{~mm}$ and standard deviation of $1.5 \mathrm{~mm}$. The vegetation properties can be considered constant during the period of both storm events.
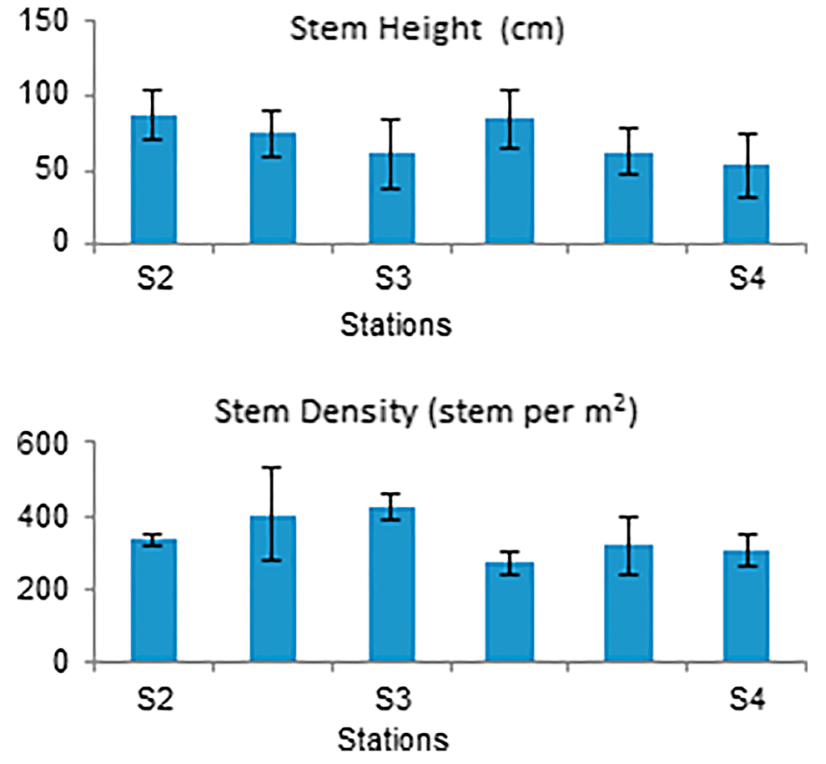

Figure 4. Blue bars represent stem density and height (constant during the storm events) reported at each sample station during the survey conducted on October 2015 at the study area. The vertical error lines show the standard deviation.

\subsubsection{Models for Wave Attenuation}

Mendez \& Losada's expression based on linear wave theory and extended for random waves was selected to predict wave propagation over a vegetated field. They derived a bulk drag coefficient formulation based on a wave damping coefficient $(\beta)$, plant characteristics, and sea state parameters:

$$
\frac{H_{r m s}}{H_{r m s, 2}}=\frac{1}{1+\beta x}
$$

$$
C_{d}=\frac{3 \sqrt{\pi}}{\varnothing N H_{r m s, 2} k} \frac{(\sinh [2 k h]+2 k h) \sinh [k h]}{\sin h^{3}\left[k l_{d}\right]+3 \sin \left[h k l_{d}\right]} \beta
$$

where $x$ is the cross-shore distance inside the vegetated region, $H_{\mathrm{rms}}$ is the root-mean-square wave height at a given location, $H_{\mathrm{rms}, 2}$ is the rootmean-square wave height at the front of the vegetation field (S2), $h$ is the water depth, $k$ is the wave number, $\varnothing$ is the stem diameter, $N$ is the stem density, $l_{d}$ is the stem deflected length, and $\pi$ is the pi number. The stem deflected length was considered equal to the stem length since as it was observed by the authors in the field, the bending angle of the S. alterniflora was very low. Likewise, Losada et al. (2016) observed that the mean bending angle for $S$. anglica was almost zero. Similar 
approach was followed in previous studies (Anderson \& Smith, 2014; Knutson et al., 1982; Maza et al., 2015; Vuik et al., 2016; Wu \& Cox, 2015; Ysebaert et al., 2011) involving this vegetation species (real or synthetic). Equation (2) was used to obtain the wave damping coefficient, $\beta$, where this coefficient was calibrated to best fit the wave height observations obtained from the high-frequency pressure data loggers time series measured during the first event. Once $\beta$ is calculated, equation (3) was used to calculate the drag coefficient, $C_{d}$, considering wave and vegetation conditions for each sea state.

For predictive purposes, drag coefficient was expressed as a function of the Reynolds number, Re; the Keulegan-Carpenter number, $\mathrm{KC}$; and the relative depth, $h_{r}$, defined in equations (4) and (5). The empirical relationship between $C_{d}$ and these three nondimensional numbers were obtained following the form proposed by Kobayashi et al. (1993). Parameters $a, b$, and $c$ were adjusted to best fit on each drag coefficient expression.

$$
\begin{gathered}
C_{d}=a+\left(\frac{b}{\mathrm{Re}}\right)^{c}, C_{d}=a+\left(\frac{b}{\mathrm{KC}}\right)^{c}, \text { and } C_{d}=a+\left(\frac{b}{h_{r}}\right)^{c} \\
\operatorname{Re}=\frac{\varnothing \mathrm{V}_{\mathrm{c}}}{v}, \mathrm{KC}=\frac{\mathrm{V}_{\mathrm{c}} \mathrm{T}_{\mathrm{p}}}{\varnothing}, \text { and } \mathrm{h}_{\mathrm{r}}=\frac{\mathrm{h}}{\mathrm{l}_{\mathrm{d}}}
\end{gathered}
$$

$V_{c}$ is the maximum orbital velocity acting on the top of the canopy and calculated using wave linear theory (see Anderson \& Smith, 2014; Losada et al., 2016; Maza et al., 2015; Mendez \& Losada, 2004 for further details), and $v$ is the kinematic viscosity of the water $\left(10^{-6} \mathrm{~m} / \mathrm{s}\right)$.

The hydrodynamic information obtained during the first event was used to evaluate the marsh edge effect on the wave propagation. Empirical representations were derived to estimate wave height attenuation from S1 to S2 as a function of the incoming wave height and water depth above the marsh platform. These expressions included all nonlinear effects produced in the wave propagation as the result of currents, shoaling, reflection, and other processes, which cannot be solved analytically. The data measured during the first event were also employed to estimate damping and drag coefficients (equations (2) and (3)), and ultimately, to obtain the coefficients for the expressions on equation (4). The information collected during the second event, which was only measured by the Aquadopps, was used to evaluate the ability of the previously derived expressions on representing wave propagation along the marsh edge and the vegetation field under different hydrodynamic conditions. Thus, wave heights observed at the Aquadopp 2 were compared against the wave heights computed at the same location. The root-mean-square error was used to quantify the discrepancies between the computed and observed wave heights.

The representation of the wave propagation across the marsh edge using these empirical representations is a limitation of this validation process. Furthermore, the formulation and validation of these expressions were carried out based on $H_{\text {rms }}$ and $H_{S}$ assuming a Rayleigh distribution.

\section{Results}

\subsection{Wave and Current Interactions Seaward}

Wave direction, current magnitude (total velocity), and direction were extracted from the Aquadopp at the seaward location and plotted in the top panel of Figure 5. Velocity magnitude was averaged through the water column resulting in maximum velocities of $0.6 \mathrm{~m} / \mathrm{s}$. Currents were mostly toward the western direction (going into the bay) and reorientated toward the eastern direction only during the lower part of the tidal cycle. Current directions were not completely aligned to the marsh platform shoreline, but they closely followed the general orientation of the shoreline, considering the long island located in front of the study area. Waves approaching the study site were affected by refraction and they reached the marsh platform perpendicularly.

Figure 5 also displays higher total velocities observed during ebb tides in comparison to flood tides. For instance, on the $27 \mathrm{th}$, the total velocities measured during ebb tides ranged between 0.28 and $0.57 \mathrm{~m} / \mathrm{s}$, while during flood tides total, total velocities varied between 0.14 and $0.25 \mathrm{~m} / \mathrm{s}$. On the other hand, when analyzing $H_{S}$ on the same day, waves measured at S1 during flooding were around $0.25 \mathrm{~m}$, while $H_{S}$ during ebb were significantly lower, up to $0.08 \mathrm{~m}$. Same behavior was observed during the rest of the storm. 

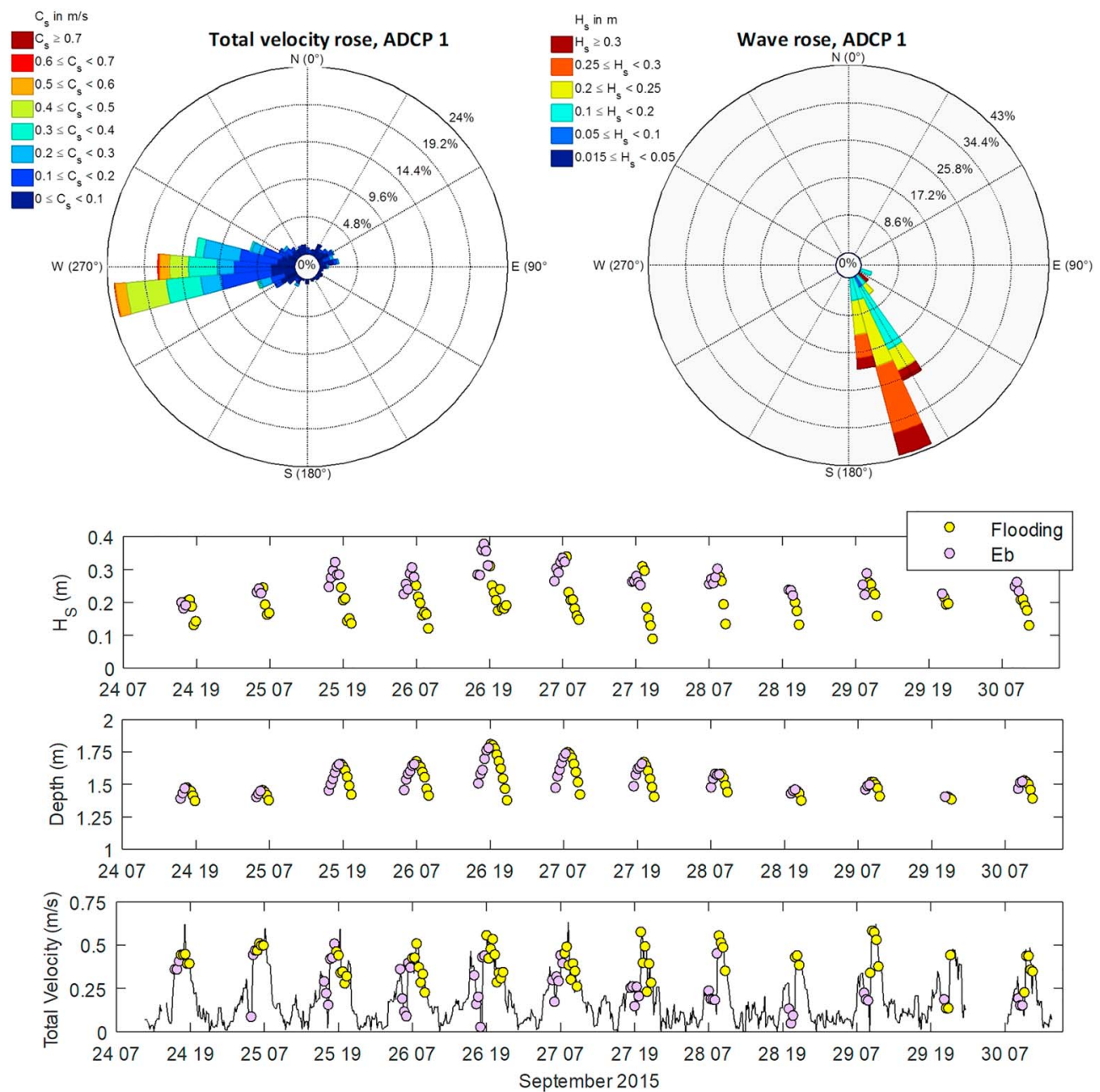

Figure 5. Total velocity rose and wave rose measured by the seaward Aquadopp. Wave direction represents the direction where they are coming from and current direction reveals going toward. Bottom plots display the $H_{S}$ and water depth measured at the S1 and the total average velocity recorded by the Aquadopp 1. The yellow and violet dots represent the observations during the ebb and flood tides, respectively, and the black line the total velocity.

Therefore, lateral currents might be impacting the approaching waves differently during the flood tides and the ebb tides based on the current magnitude. It resulted in higher ratios of $H_{S, 2} / h$ during flood than during ebb tides.

\subsection{Marsh Edge Effect on Wave Propagation}

The impact of the marsh edge on the wave propagation is shown in Figure 6. Wave heights were attenuated differently depending on the water depth and the incoming wave height in the transition between S1 and S2. Wave attenuation was higher with lower water depths over the marsh platform. For example, between S1 and S2, wave heights of $0.25 \mathrm{~m}$ reaching the marsh platform under $0.55-0.60-\mathrm{m}$ water depths were attenuated by around $30-40 \%$ of the incoming wave height, while similar wave heights were only attenuated by $15 \%$ under 0.85-0.90-m water depths. Interestingly, the wave attenuation between S1 and S2 exhibited a linear relationship with incident wave height S1, showing a moderate agreement, especially for the highest water depth $\left(\rho^{2}=0.83\right)$.

\subsection{Wave and Current Interactions at the Marsh Platform}

Wave direction and current velocity magnitude (total velocities) and current direction were recorded by the ADCP 2, located at the marsh side. The wave rose shown in Figure 7 demonstrates that the waves propagated 


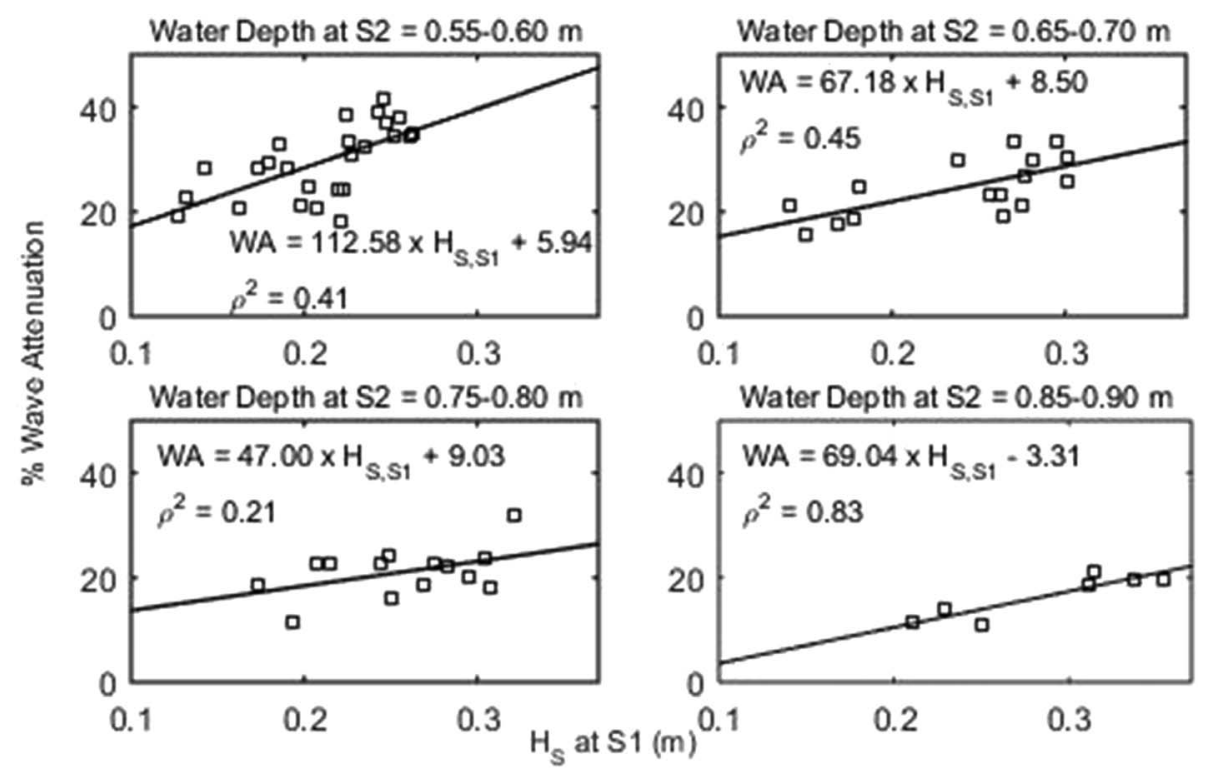

Figure 6. Edge effect on wave propagation. Wave heights attenuation between S1 (seaward) and S2 (at the edge) as a function of incident wave $\left(H_{S}\right.$ at S1). The mathematical expressions provide wave attenuation (WA) values as a function of the $H_{S}$ at sensor $1\left(H_{S, S 1}\right) \cdot \rho^{2}$ represents the correlation coefficient.

in almost the same directions as those recorded at the ADCP 1 , being slightly refracted about $10-15^{\circ}$. However, currents exhibited different directions than at the seaward. During flood tides, currents rotated about $120^{\circ}$, while during ebb tides, they almost maintain a constant direction. The total velocity time series analysis (see Figure S2 in the supporting information for more information) demonstrated that at the beginning of the tidal cycle, currents were going toward N and NNW direction and then, progressively rotated counterclockwise reaching the SW direction, as it was also observed by Chen et al. (2016). The variation of the current direction during the ebb tides was limited and maintained almost a SW-S direction. Similarly to the ADCP 1, total velocities were higher during the ebb than the flood tides. While Figure 7 demonstrated that currents and waves were not totally collinear inside the marsh, in the following sections we will explore the effects of the north component of the total current velocity on the wave propagation inside the vegetation field. Thus, sea states were grouped into (1) following currents, when the north component of the total current velocity was positive, and (2) opposing currents, when the north component of the total velocity was negative (going toward south).

\subsection{The Effects of Varying Hydrodynamic Conditions on Wave Attenuation Within the Marsh Platform}

It is well known that hydrodynamic conditions, such as wave height, water depth, or relative water depth, play a significant role on wave damping induced by vegetation (Anderson \& Smith, 2014; Maza et al., 2015). In order to analyze the influence of these different parameters in the induced wave attenuation, equation (2) was used to fit the damping coefficient $(\beta)$. Figure 8 shows the best fitted parameters and the associated damping coefficient for cases with different wave heights and four water depths. The calculated $\beta$ were plotted in Figure 9 as a function of $h_{r}$, separating the cases based on the north component of the velocity: following currents (observed during flood tides) and opposing currents (observed at the last part of the flood tides and at the ebb tides). A clear difference was noticed on the incident relative wave height at station $2\left(H_{S, 2} / h\right)$ on Figure 9; the incident relative wave height was higher for following currents than for the opposing currents, as the result of higher current velocities during ebb tides than flood tides that affected the incoming waves at the seaward (see Figure 5). This might corroborate the hypothesis that the strong lateral currents highly affected the approaching waves before reaching the marsh platform. Furthermore, cases with $h_{r}<1$ have been considered to account for the additional 

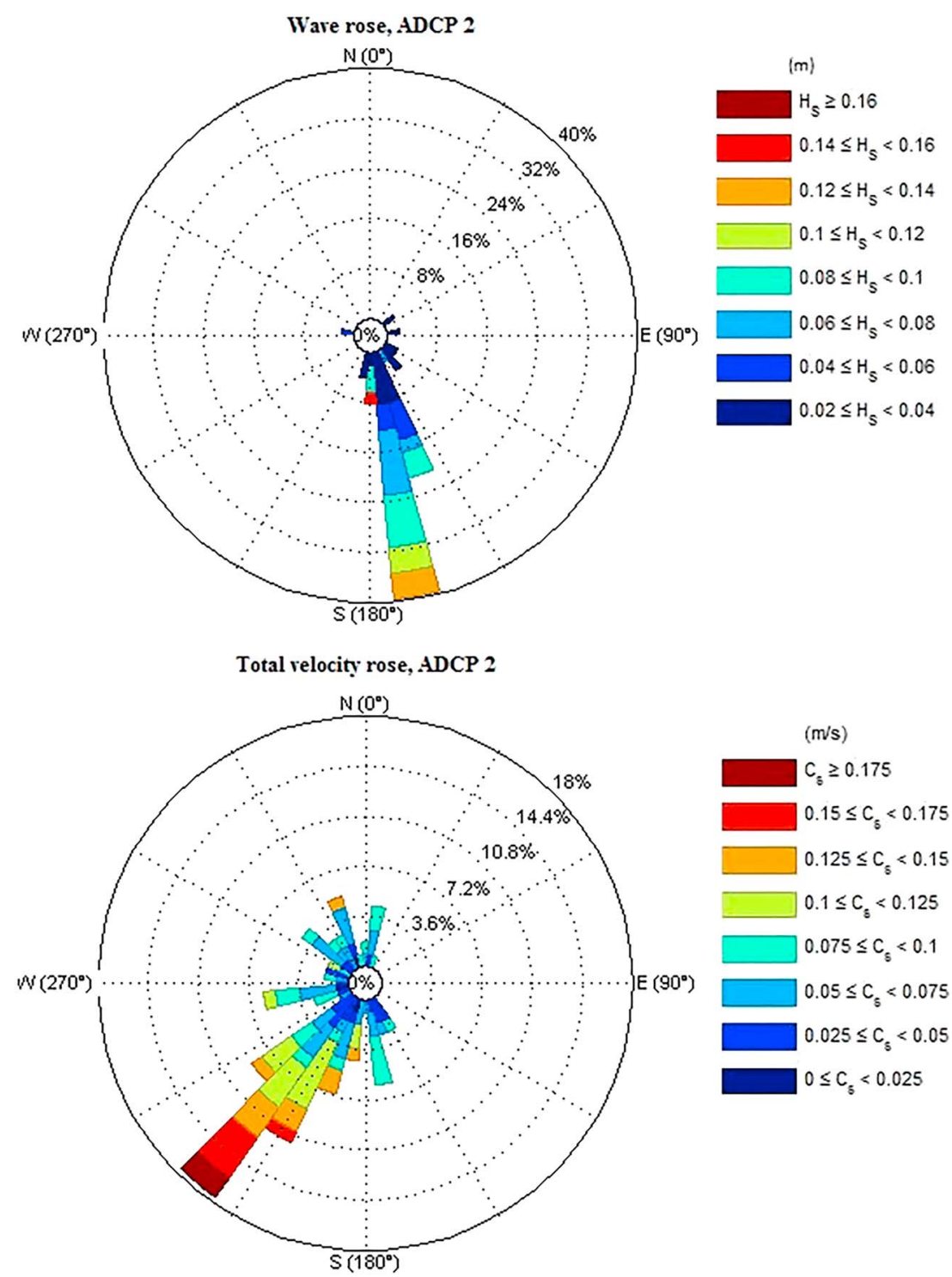

Figure 7. (top) Wave rose and (bottom) total velocity rose measured at the Aquadopp 2 (marsh side). Wave direction represents the direction where the waves are coming from and current direction reveals going toward.

dissipation produced by the vegetation above mean sea level. Thus, waves were travelling on water surface and the effective stem length generating the drag force varied depending on the wave phase. For instance, if there was a crest impacting the vegetation stem, the actual total water depth was the water depth plus the wave amplitude.

The dependence of frequency on wave energy dissipation was also explored following Bradley and Houser (2009). Figure 10 shows the wave energy attenuation between S2 and S4 against frequencies for four cases, separating in following and opposing currents. First, the wave energy spectrum data set was clustered based on the water depth (0.5-0.6, 0.6-0.7, 0.7-0.8, and 0.8-0.9 m). Second, the wave energy measured for each of those water depths was averaged. Finally, the wave energy dissipation was estimated by

$$
\frac{\partial E C_{g}}{\partial x}=-S_{v}
$$

where $E$ is the wave energy, $C_{g}$ is the group celerity, and $S_{v}$ is the dissipation by vegetation. $C_{g}$ is defined by the phase speed and the parameter $n$ that depends on the frequency and water depth. 

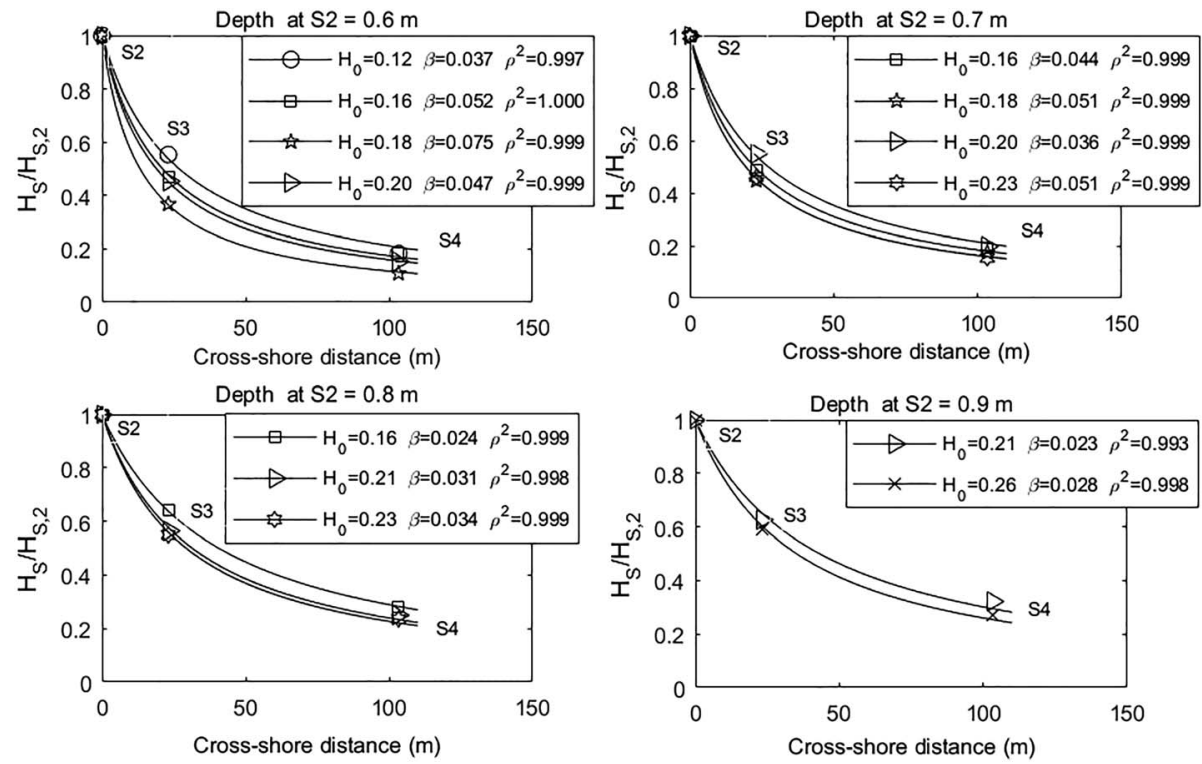

Figure 8. Wave damping between S2 and S4 illustrated under different environmental conditions. Each panel shows results for a specific water depth and different wave conditions (different symbols). Fitting lines are displayed and the associated $\beta$ and $\rho^{2}$ are shown. These examples were selected during the entire storm event.

Figure 10 displays that the wave energy dissipation was not uniform along the frequencies, but most of the energy was dissipated on the frequencies between 0.10 and $0.40 \mathrm{~Hz}$, where the largest energy was observed on the wave energy spectrum. Table 1 shows that the wave energy dissipation was higher during following than opposing currents (up to 50\%), and this also aligns with the differences found between following and opposing currents cases and the associated different fits in Figure 9. Following currents lead to more energetic short waves reaching the marsh and these waves were more attenuated as observed in Figure 10.

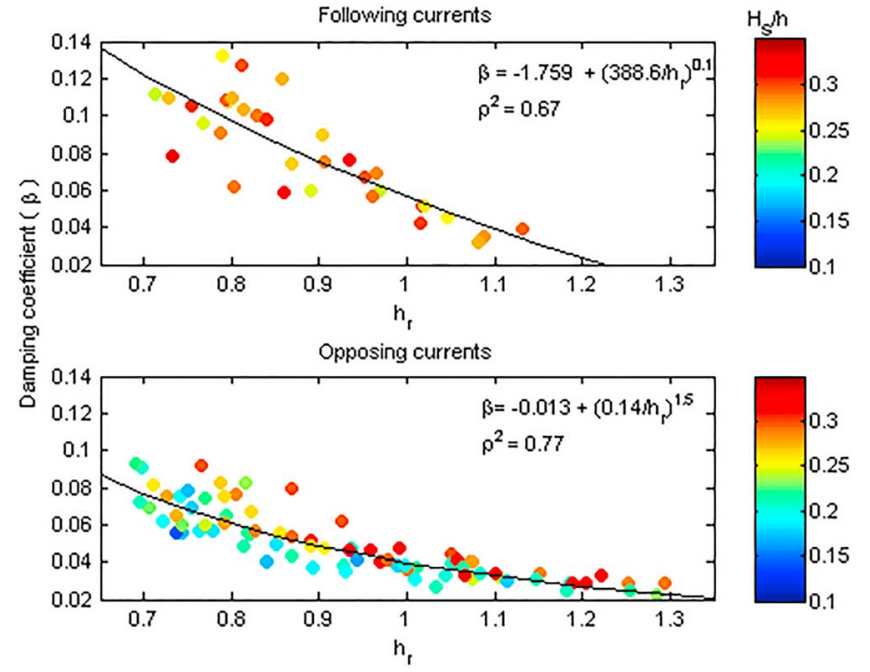

Figure 9. Wave damping coefficient as a function of the $h_{r}\left(h / l_{d}\right)$ at S2 (marsh platform) for following and opposing currents. The markers are colored by the $H_{S, 2} / h$. Water depth over the marsh platform is represented by $h$.

\subsection{Bulk Drag Coefficient Formulation}

Drag coefficients, $C_{d}$, associated to each $\beta$ are obtained using equation (3). The relationship of the $C_{d}$ with Reynolds number, Keulegan-Carpenter number, and relative water depth was studied following equations (4) and (5). Figure 11 shows the relationships obtained differentiating between following and opposing currents. Moreover, following the Nepf (2004) definition, the data set was classified into near-emergent $\left(h / l_{d}\right.$ $>1$ ) and emergent $\left(h / l_{d}<1\right)$. A higher scatter of $C_{d}$ was clearly noticed on the emergent data than the near-emergent data for those three parameters assessed. When using the Reynolds number approach, higher $C_{d}$ values were observed with following than opposing currents, especially for lower Re numbers. For instance with $\operatorname{Re}=1,000$, the $C_{d}$ values were 2.89 and 1.41, respectively, while with $\mathrm{Re}=1,500, C_{d}$ were 1.08 and 0.85 . Thus, the slope of the fitted curve for the values obtained with following currents was higher than the one obtained for opposing currents. This indicates that $C_{d}$ were more sensitive to changes in Re with following currents. Furthermore, the relationship with Re exhibited similar agreement $\left(\rho^{2}=0.52-0.54\right)$ with both cases. When focusing on the KC number plots, it was found that (1) the relationship with $C_{d}$ revealed a worse agreement than with $\mathrm{Re}$, with $\rho^{2}$ values of 0.39 (following) and 0.25 (opposing), and (2) similar $C_{d}$ values were obtained with following and opposing currents, with only significant differences for low $\mathrm{KC}$ number 

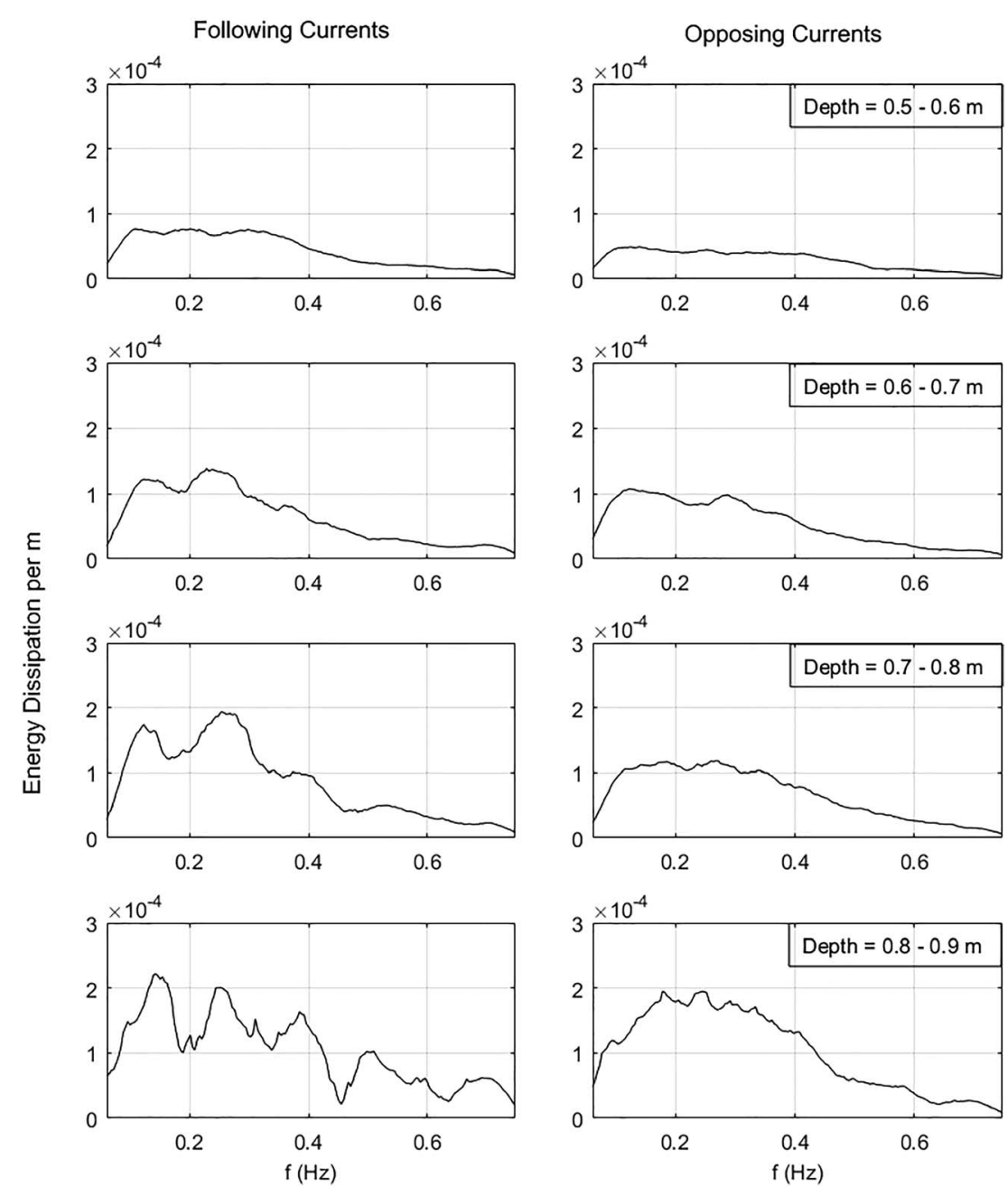

Figure 10. Wave energy dissipation calculated between $\mathrm{S} 2$ and $\mathrm{S} 4$ against frequencies calculated at four water depths during following and opposing currents.

(KC $<180)$. Finally, the relationship of $C_{d}$ with $h_{r}$ showed a fairly good agreement, with higher correlation for opposing currents $\left(\rho^{2}=0.77\right)$ than for following currents $\left(\rho^{2}=0.60\right)$. Similarly to the relationship between $C_{d}$ and Re, higher $C_{d}$ were reported with following than opposing currents, and a steeper slope was observed for the case of following currents.

The fair dependency of $C_{d}$ with respect to $h_{r}$ shown in Figure 11 (correlation coefficients equal to 0.6-0.77) would suggest that Re and KC might be modified to consider the relative water depth, as proposed by Mendez and Losada (2004). Following their approach, the modified Re and KC numbers $\left(\mathrm{Q}_{\mathrm{Re}}\right.$ and $\mathrm{Q}_{\mathrm{KC}}$ ) were used as predictors in this study. The new predictors were defined as

Table 1

Wave Energy Dissipation Between Station 2 and Station 4

\begin{tabular}{lccc}
\hline $\begin{array}{l}\text { Depth } \\
(\mathrm{m})\end{array}$ & $\begin{array}{c}\text { Dissipation per m } \\
\text { following currents }\end{array}$ & $\begin{array}{c}\text { Dissipation per } \mathrm{m} \\
\text { opposing currents }\end{array}$ & $\begin{array}{c}\% \\
\text { difference }\end{array}$ \\
\hline $0.5-0.6$ & $3.04 \times 1.0^{-05}$ & $2.02 \times 1.0^{-05}$ & 50 \\
$0.6-0.7$ & $4.41 \times 1.0^{-05}$ & $3.77 \times 1.0^{-05}$ & 17 \\
$0.7-0.8$ & $5.90 \times 1.0^{-05}$ & $4.63 \times 1.0^{-05}$ & 27 \\
$0.8-0.9$ & $7.16 \times 1.0^{-05}$ & $7.02 \times 1.0^{-05}$ & 2 \\
\hline
\end{tabular}

$$
\mathrm{Q}_{\mathrm{Re}}=\frac{\mathrm{Re}}{\left(\mathrm{h}_{\mathrm{r}}^{-1}\right)^{\Psi}} ; \quad \mathrm{Q}_{\mathrm{KC}}=\frac{\mathrm{KC}}{\left(\mathrm{h}_{\mathrm{r}}^{-1}\right)^{\Omega}}
$$

where $\Psi$ and $\Omega$ were the exponents providing the best fit simultaneously with following and opposing currents. The modified nondimensional numbers clearly enhanced the correlation coefficients and these new formulations presented $\rho^{2}$ varying between 0.68 and 0.78 (see Figure 12). The improvement obtained for the modified $\mathrm{KC}$, which displayed the weakest 

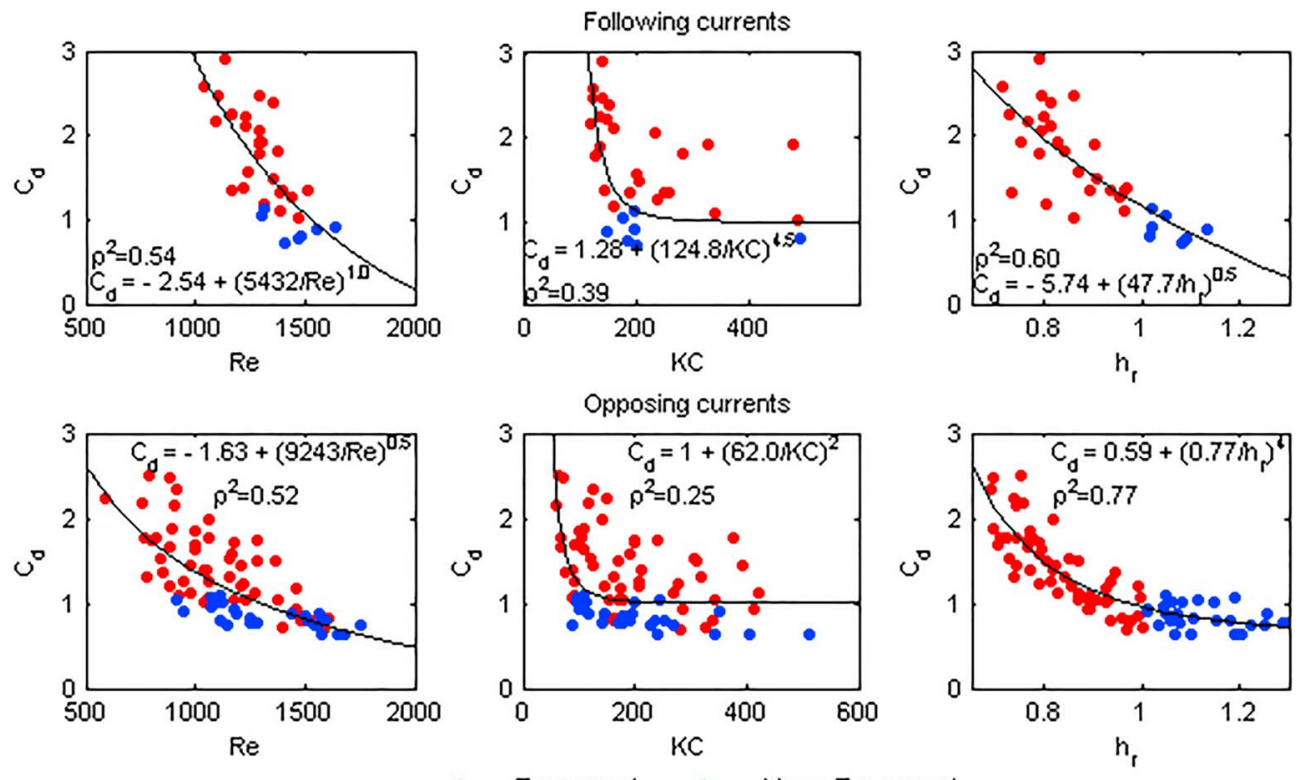

- Emergent - Near-Emergent

Figure 11. Drag coefficient as a function of the Re number, KC number, and $h_{r}$ for (top plot) following and (bottom plot) opposing currents. Red dots represent emergent conditions and blue dots display near-emergent conditions.

relationship in Figure 11, was especially noticeable. Similarly to the wave damping coefficient and $C_{d}$ adjustments shown in Figures 9 and 11, $h_{r}$ values lower than 1 were considered on the expressions displayed in equation (7).

In oder to provide a more generic formulation that can be used under both, following and opposing currents, $C_{d}$ was expressed as a function of $\mathrm{Q}_{\mathrm{Re}}$ and $\mathrm{Q}_{\mathrm{Kc}}$ considering all cases. The calculated fittings are displayed in the two bottom panels of Figure 13 and they were obtained using $\Psi$ equal to 5 and $\Omega$ equal to 9 in equation (7):
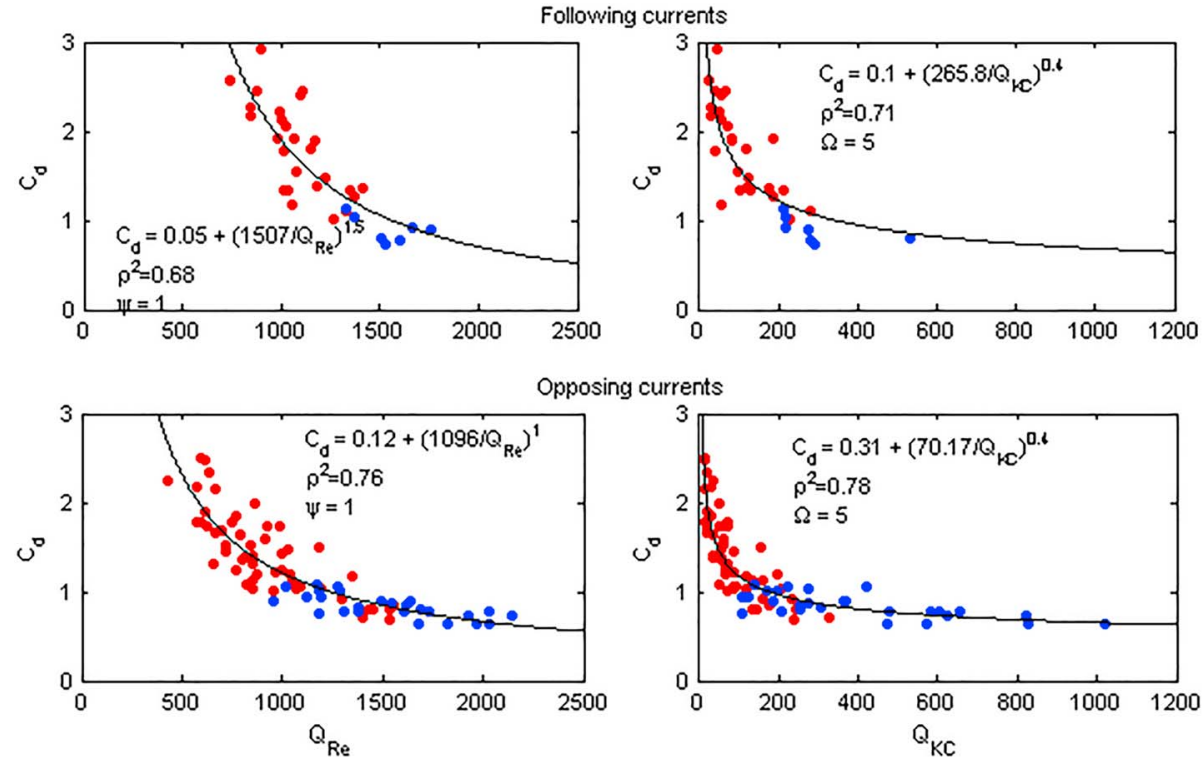

Figure 12. Drag coefficient as a function of the modified Re number and KC number for (top plot) following and (bottom plot) opposing currents. 

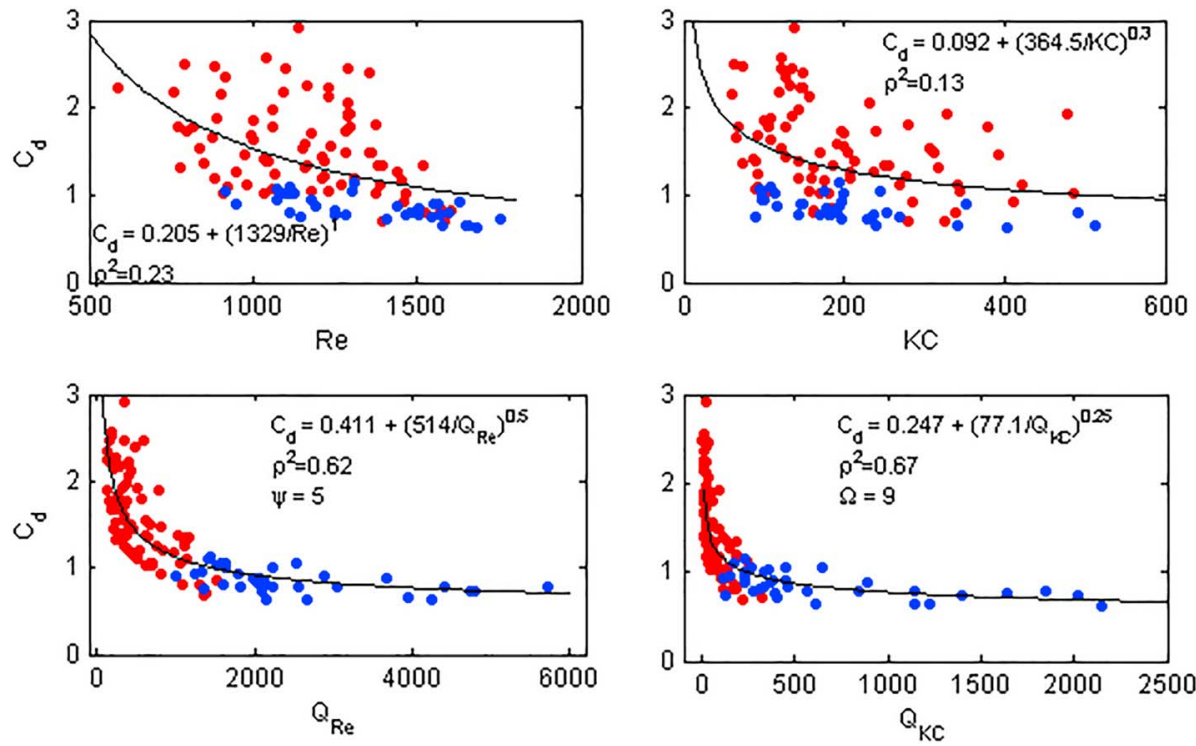

Figure 13. Drag coefficient as a function of the (top plot) traditional and (bottom plot) modified Re number and KC number. Red dots represent emergent conditions and blue dots display near-emergent conditions. This figure includes both opposing and flowing currents.

$$
\begin{gathered}
C_{d}=0.411+\left(\frac{514}{\mathrm{Q}_{\mathrm{Re}}}\right)^{0.5}, \Psi=5 ; \\
C_{d}=0.247+\left(\frac{77.1}{\mathrm{Q}_{\mathrm{KC}}}\right)^{0.25}, \Omega=9 ;
\end{gathered}
$$

These new expressions were compared to those expressions obtained using the traditional Re and KC numbers considering following and opposing currents simultaneously. Figure 13 shows the resulting fittings and it can be observed that $C_{d}$ correlated better to $\mathrm{Q}_{\mathrm{Re}}$ and $\mathrm{Q}_{\mathrm{KC}}$ than to $\mathrm{Re}$ and $\mathrm{KC}$.

\subsection{Model Validation}

The formulations derived during the first event ocurring from 24 to 30 September (pressure data loggers) were validated against the measurements recorded during the second event ocurring from 1 to 5 October. These measurement were taken by the high-frequency pressure loggers installed in the two Aquadopps (seaward and at the marsh platform).

First, the equations obtained in Figure 6 were applied to infer the wave propagation from seaward to the marsh edge based on the water depth and the wave height measured at the Aquaddopp 1. Second, $C_{d}$ were calculated as a function of (1) $\mathrm{Q}_{\mathrm{Re}}$ and $\mathrm{Q}_{\mathrm{KC}}$ following the expressions shown in Figure 12 and (2) by applying equations (8) and (9). Third, $\beta$ coefficients were obtained based on equation (3), which take into account the $C_{d}$ previously calculated, sea state conditions, and plant characteristics. Finally, wave heights at the location of the marsh side Aquadopp were estimated following equation (2). Wave heights obtained with this methodology were then compared against wave heights recorded at the Aquadopp located at the marsh (Figure 14).

Top panels in Figure 14 show the wave heights obtained using the equations obtained distinguishing between following and opposing currents displayed in Figure 12. Bottom panels in the same figure show the wave heights calculated by using equations (8) and (9), which do not discriminate between current directions. The four scatterplots show a good agreement between the computed and measured wave heights at the marsh side Aquadopp. $\mathrm{Q}_{\mathrm{Re}}$-based plot using the equation in Figure 12 exhibited a slightly better performance than the rest of the adjustments. Overall, the equations derived in this study perform significantly well for the smaller waves and some overprediction was observed in the largest measured waves. The root-mean-square error varied between 0.013 and $0.014 \mathrm{~m}$ with the errors observed at the largest values 


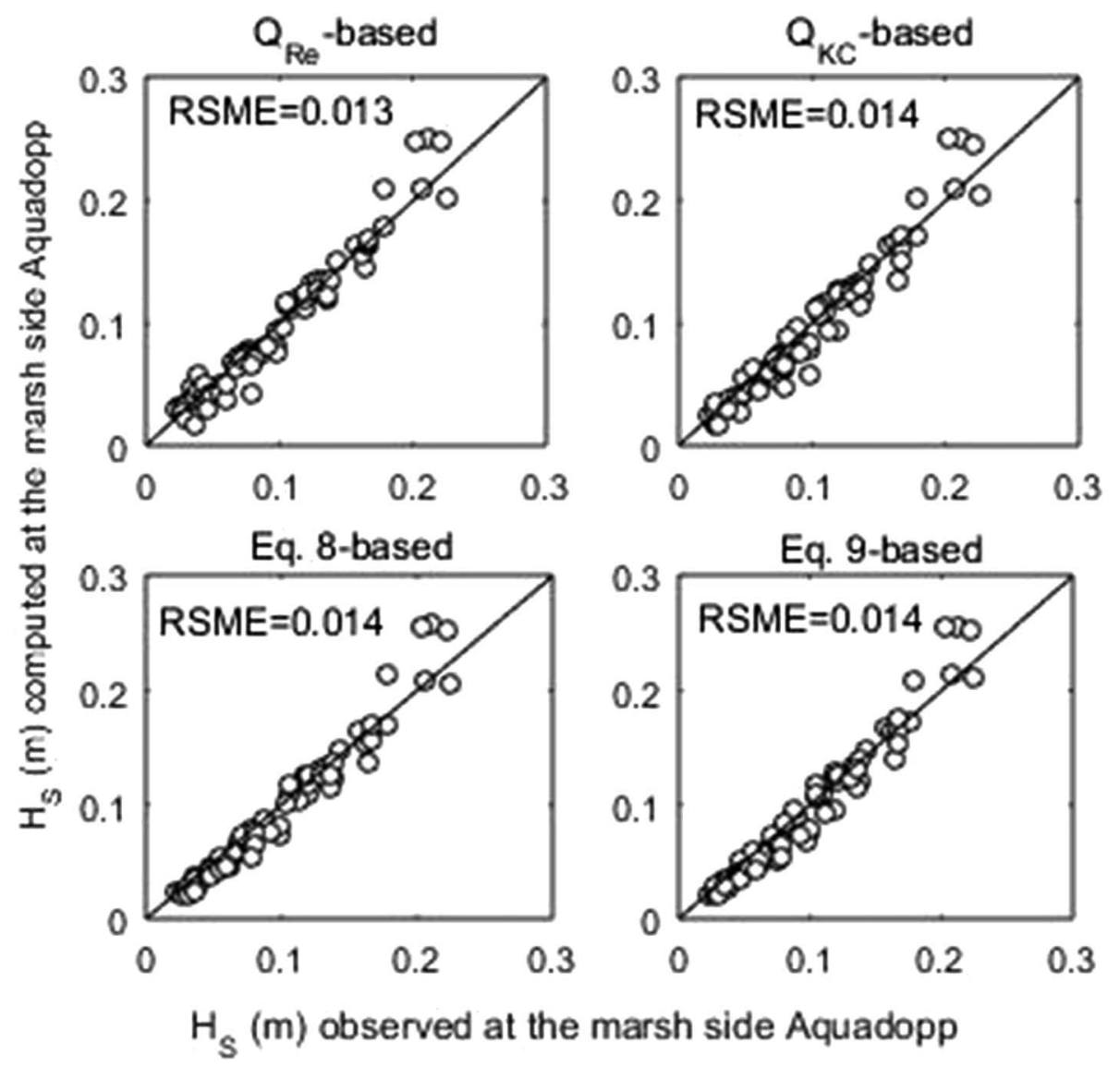

Figure 14. $H_{S}$ observed against computed at the marsh side Aquadopp. Scatterplots shown on the top panels are based on the equations in Figure 12 (i.e., separating into opposing/following currents), while bottom plots are based on equations (8) and (9), which consider both cases together.

(0.21-0.22 $\mathrm{m}$ ) ranging between $9.0 \%$ (underprediction) and $18.2 \%$ (overprediction). Note that these errors are not only applicable to the drag coefficient formulations but also to the equations provided in Figure 6.

\section{Discussion}

\subsection{Wave Propagation Outside the Marsh Platform}

The interactions between waves and lateral currents resulted in higher wave heights during flood conditions when the current velocities were lower. Conversely, stronger current velocities during ebb conditions caused lower wave heights reaching the marsh platform. These interactions were also study by Liu (1983). He derived an analytical expression to account for wave and lateral or alongshore current interactions and demonstrated that lateral currents reduced the local wave amplitude; meanwhile without lateral currents, the wave amplitude increased due to shoaling.

The role of the marsh edge on the overall wave attenuation by marshes in coastal areas has not been widely studied in the current literature. At the marsh edge, the incoming wave energy might be affected by complex processes such as wave energy reflection by the edge face, wave shoaling induced by a sudden decrease in water depth, and surface roughness. Möller and Spencer (2002) explored the effect of the marsh edge topography on wave energy reduction and stated that a cliff edge dissipates twice the energy ( $8 \%$ per meter) of a noncliff edge ( $4 \%$ per meter). However, the edge did not significantly impact the overall wave energy dissipation and the wave energy reduction inside the vegetated marsh. Later, Möller (2006) also demonstrated that water depth controlled wave attenuation at the marsh edge, as it has been also demonstrated in Figure 6. Additionally, Yang et al. (2012) reported water levels, along with wave heights, at the seaward and landside (mudflat) for a marsh edge of $0.27 \mathrm{~m}$ during four tidal cycles. They also showed the strong influence of the water depth when analyzing the edge effect on the waves, revealing that no significant 
differences were observed for the highest tidal cycle (more than $1.5 \mathrm{~m}$ at the seaward). For instance, approaching waves with heights of $0.15 \mathrm{~m}$ over $0.9 \mathrm{~m}$ of water depths were attenuated up to $0.10 \mathrm{~m}(50 \%)$ after crossing the edge; while approaching waves with heights of $0.2 \mathrm{~m}$ propagating over a $1.2-\mathrm{m}$ water column were only reduced $0.025 \mathrm{~m}(12.5 \%)$ at the edge.

In the present study, incoming waves with heights of 0.25 and $0.35 \mathrm{~m}$ propagating over $1.75 \mathrm{~m}$ of water depths were attenuated at the marsh edge up to $12 \%$ and $20 \%$, respectively (Figure 6). Similarly to previous studies, water depth highly influenced wave transmission at the marsh edge, between S1 and S2, lower depths caused smaller energy transmission into the marsh. This modification of the incident wave conditions was the result of the combination of nonlinear effects mainly induced by seaward currents, shoaling, dissipation by vegetation ( $4 \mathrm{~m}$ from the edge to the sensor), and reflection, which were more intense for smaller water depths.

\subsection{The Effects of Varying Hydrodynamic Conditions on Wave Attenuation Within the Marsh Platform}

Currents at marsh platform, water depth, and the relative incident wave height, $H_{S, 2} / h$, highly influenced wave attenuation along the marsh. For instance, the present study demonstrated that when applying the distinction between current directions, wave damping coefficients can be properly represented as a function of $h_{r}$ when separating between currents following waves and currents opposing waves. Maza et al. (2015) also explored the role of current directions on wave attenuation. They reported different damping coefficients for waves and currents depending on the current direction within a Spartina meadow. They observed lower attenuation on tests with currents and waves flowing at the same direction than cases with only waves. Moreover, waves and currents in opposite directions resulted in larger attenuation rates (Maza et al., 2015). Losada et al. (2016) also demonstrated the importance of current direction and the associated Doppler effect on the wave propagation. At the present study, following cases displayed larger attenuation than opposing cases. This might be explained by the larger ratios of $H_{S, 2} / h$ observed during following currents in comparison to opposing currents, as shown in Figure 9 and the nonlinear interactions between waves and currents (Losada et al., 2016). However, the effect of currents on the wave attenuation was limited since the experiment was carried out under weak current conditions (Thomas \& Klopman, 1997). This fact was confirmed by the agreement displayed in the bottom plots of Figure $13\left(\rho^{2}=0.62-0.67\right)$, where both current conditions (following and opposing) were considered together.

The relative water depth significantly impacted the wave attenuation. During emergent conditions $\left(h_{r}<1\right)$, wave damping coefficients were remarkably higher than during near-emergent conditions $\left(h_{r}>1\right)$, as demonstrated in Figure 9. This effect was also observed in former studies (Anderson \& Smith, 2014; Augustin et al., 2009; Maza et al., 2015; Ysebaert et al., 2011). For instance, Anderson and Smith (2014) noticed on their physical experiments that the wave height decay coefficients exhibited a large sensitivity to submergence state changes. During emergent conditions, the vegetation is occupying the entire water column (assuming that the stem length is longer than the sum of the wave amplitude and the still water depth), implying a strong wave-vegetation interaction. Conversely, the plant stem does not obstruct the highest orbital velocities observed at the top portion of the water column during submerged conditions (Augustin et al., 2009). Furthermore, the present study demonstrated that the decrease of the wave damping coefficients with higher relative water depths was quicker in shallow water conditions, as indicated also by Anderson and Smith (2014), and our $\beta$ coefficients tended toward an asymptote to about 0.02 with $h_{r}>1.2$, especially with opposing currents. Maza et al. (2015) and Ysebaert et al. (2011) found a logarithmic expression that related water depth and wave attenuation. Here we modified that expression resulting in higher $\rho^{2}$ coefficients (see Figure 9). The agreement of the fitted expression was, in general, very high (0.67-0.77), with slightly better agreement with opposing than following currents. The high dispersion of wave damping coefficient found for cases with $h_{r}$ lower than 1 might be associated to the discrepancies between the $h_{r}$ used in Figure 9 and the actual water depth that accounted for the water depth and the wave amplitude.

This study also revealed that higher wave damping coefficients were observed with larger ratios of $H_{S, 2} / h$. These findings are in agreement with Möller (2006), which observed that higher ratios increased the wave attenuation based on field measurements. Anderson and Smith (2014) also demonstrated that under constant water depth conditions, larger waves were more attenuated than smaller waves in a laboratory experiment. However, Anderson and Smith (2014) also observed that the differences in the attenuation rates 
Table 2

Study, Experiment Characteristics, Vegetation Type, Hydrodynamic Conditions, Specie, Stem Density $\left(n / m^{2}\right)$, and Damping Coefficient (Standard Deviation Is Given in Parenthesis)

\begin{tabular}{|c|c|c|c|c|c|c|c|c|}
\hline Publication & Characteristics & Case & Vegetation & $H_{S} / L_{P}$ & $h / l_{d}$ & $H_{S} / h$ & $N$ & $\beta$ coefficient \\
\hline Maza et al. $(2015)^{\mathrm{a}}$ & 3-D flume (no currents) & Irregular & Spartina anglica & 0.04 & 1.40 & 0.30 & 430 & 0.081 \\
\hline Maza et al. (2015) ${ }^{\mathrm{a}}$ & 3-D flume (following) & Irregular & Spartina anglica & 0.04 & 1.40 & 0.30 & 430 & 0.036 \\
\hline Maza et al. (2015) ${ }^{\mathrm{a}}$ & 3-D flume (opposing) & Irregular & Spartina anglica & 0.04 & 1.40 & 0.30 & 430 & 0.095 \\
\hline Wu and Cox (2015) & 2-D flume (no currents) & Irregular & Idealized & 0.010 & 0.85 & 0.13 & 2100 & 0.31 \\
\hline Wu and Cox (2015) & 2-D flume (no currents) & Irregular & Idealized & 0.014 & 0.85 & 0.20 & 2100 & 0.45 \\
\hline $\mathrm{Wu}$ and Cox $(2015)^{\mathrm{b}}$ & 2-D flume (no currents) & Irregular & Idealized & 0.019 & 0.85 & 0.28 & 2100 & 0.56 \\
\hline $\mathrm{Wu}$ and Cox $(2015)^{\mathrm{b}}$ & 2-D flume (no currents) & Irregular & Idealized & 0.024 & 0.85 & 0.34 & 2100 & 0.61 \\
\hline Present study & Field (following) & Irregular & Spartina alterniflora & 0.017 & 0.76 & 0.27 & 344 & $0.104(0.014)$ \\
\hline Present study & Field (following) & Irregular & Spartina alterniflora & 0.017 & 0.83 & 0.28 & 344 & $0.091(0.024)$ \\
\hline Present study & Field (following) & Irregular & Spartina alterniflora & 0.018 & 0.94 & 0.28 & 344 & $0.071(0.013)$ \\
\hline Present study & Field (following) & Irregular & Spartina alterniflora & 0.020 & 1.04 & 0.28 & 344 & $0.042(0.007)$ \\
\hline Present study & Field (following) & Irregular & Spartina alterniflora & 0.035 & 1.13 & 0.29 & 344 & $0.039(0.000)$ \\
\hline Present study & Field (opposing) & Irregular & Spartina alterniflora & 0.014 & 0.74 & 0.22 & 344 & $0.071(0.012)$ \\
\hline Present study & Field (opposing) & Irregular & Spartina alterniflora & 0.016 & 0.83 & 0.25 & 344 & $0.056(0.012)$ \\
\hline Present study & Field (opposing) & Irregular & Spartina alterniflora & 0.020 & 0.93 & 0.21 & 344 & $0.044(0.007)$ \\
\hline Present study & Field (opposing) & Irregular & Spartina alterniflora & 0.022 & 1.04 & 0.25 & 344 & $0.036(0.005)$ \\
\hline Present study & Field (opposing) & Irregular & Spartina alterniflora & 0.04 & 1.14 & 0.24 & 344 & $0.030(0.003)$ \\
\hline Present study & Field (opposing) & Irregular & Spartina alterniflora & 0.04 & 1.25 & 0.27 & 344 & $0.028(0.003)$ \\
\hline
\end{tabular}

${ }^{\mathrm{a}}$ Maza et al. (2015) corresponding to $T_{p}=1.7 \mathrm{~s} .{ }^{\mathrm{b}}$ Values obtained from Table 2 of Wu and Cox (2015) corresponding to $T_{p}=1.6 \mathrm{~s}$.

between large and small waves under near-emergent conditions were not very significant. They suggested that the wave height effect was more influential in shallower water conditions. Our results supported these findings since the wave damping coefficients observed with following and opposing currents were very similar for $h_{r}$ larger than 1.1, although the $H_{S, 2} / h$ ratios were remarkably different. By contrast, $\beta$ coefficients observed with following and opposing currents were considerably different for $h_{r}$ lower than 0.9. This was also in agreement with the results obtained by $\mathrm{Wu}$ and Cox (2015), where for identical shallow conditions $\left(h_{r}=0.85\right)$ higher $H_{S, 2} / h$ ratios caused a considerably larger amount of wave energy dissipation. For instance, cases of 1.6- and 4.1-cm wave heights revealed $\beta$ coefficients of 0.31 and 0.61 , respectively (see Table 2).

Higher dissipation induced by S. alterniflora with larger waves under similar conditions is not fully in agreement with previous studies involving other saltmarshes or kelp meadow species with higher flexibility. For instance, Maza et al. (2015) and Bradley and Houser (2009) found that smaller waves were more attenuated for similar water depths when interacting with Puccinela maritima and Thalassia testudinum. Later, Rupprecht et al. (2017) demonstrated that orbital velocities and water depths played an important role on the bending angle, and therefore in the frontal area resisting the flow. More flexible stems might be bent by high orbital velocities, extending them in the flow direction, and therefore reducing the actual length that is affecting the flow (Losada et al., 2016). On the other hand, the S. alterniflora stiffness is much higher in comparison to the stiffness of those more flexible species, and it might result in neglecting the bending angle under these hydrodynamic conditions (Paul et al., 2016). As stated by Maza et al. (2015), the stems of this cordgrass act like a cantilever, and therefore, they do not align with the flow and have larger impact on the waves.

Table 2 documents a list of previous wave attenuation studies involving real and idealized S. alterniflora. Among all studies available in the literature to date, only those reporting $\beta$ coefficients calculated using equation (2) were considered. The data of the present study shown in Table 2 is the result of averaging significant wave heights, wavelengths, and $\beta$ coefficients of those sea states with a specific water depth $(0.5-0.6$, 0.6-0.7, 0.7-0.8, 0.8-0.9, 0.9-1.0 m). Wu and Cox (2015) conducted a two-dimension physical experiment representing the vegetation stems as plastic strips. Under emergent conditions $\left(h_{r}=0.85\right)$, they observed $\beta$ coefficients ranging between 0.31 and 0.61 , with $H_{S, 2} / h$ ratios varying from 0.13 to 0.34 . Under similar conditions, those coefficients were remarkably higher in comparison to the values shown in Table 2 in our study. The considerably larger stem density used in their laboratory experiment design $\left(N=2,100 \mathrm{stem} / \mathrm{m}^{2}\right) \mathrm{might}$ 
be a key factor to explain those larger $\beta$ coefficients, since more dense meadows efficiently attenuate wave energy (Anderson \& Smith, 2014; Maza et al., 2015). On the other hand, Maza et al. (2015) reported $\beta$ coefficients obtained during their three-dimensional laboratory experiments involving $S$. anglica with a stem density of $430 \mathrm{stem} / \mathrm{m}^{2}$. Under near-emergent conditions, $h_{r}=1.4$, and $H_{S, 2} / h$ ratios of 0.30 , they run three tests: only waves, waves and following currents, and wave and opposing currents. They noticed wave damping coefficient values of $0.081,0.036$, and 0.095 , respectively. These damping coefficients were higher than those found in the present study. For instance, under nearly similar conditions of $h_{r}=1.25$ and $H_{S, 2} / h=$ 0.27 and opposing currents, we obtained a wave damping coefficient of 0.028 . However, the wave steepness $\left(H_{S, 2} / L_{P}\right)$ in our study was lower than the wave steepness tested in Maza et al.'s (2015) experiments. Similarly, Wu and Cox (2015) observed higher attenuation with increasing wave steepness.

\subsection{Wave and Current Interactions at the Marsh Platform}

Currents and waves within the meadow during the recorded events were mostly not collinear, as is shown in Figure 7. However, the drag coefficient formulations shown in section 3.5 have been estimated using the Mendez \& Losada's formulation, which was derived considering only wave conditions without the influence of currents. The presence of currents within the meadow would indicate that other recently developed formulations such as Losada et al. (2016), which takes into account wave and current conditions, should be explored. Losada et al.'s formulation was derived under the consideration of several assumptions. Among the 10 assumptions considered in their formulation, one requires waves and currents to be travelling collinearly. Also, currents must be uniform over the water depth and alongshore the vegetation meadow (Losada et al., 2016). While their formulation accounts for both dynamics (currents and waves), it cannot be directly applied to our field data set since our data set does not conform to some of the assumptions specified by Losada et al. (2016). Furthermore, for the wave conditions measured at station 3 and current velocities mainly ranging between 0.1 and $0.2 \mathrm{~m} / \mathrm{s}$ within the marsh platform, it was concluded that this experiment was carried out under the hypothesis of a weak current regime (Thomas \& Klopman, 1997). On the other hand, Figures 11-13 of the manuscript demonstrates that hydrodynamic numbers (KC and $\mathrm{Re}$ ) can properly predict the $C_{d}$ calculated following Mendez and Losada (2004) with an agreement of almost $80 \%$. Furthermore, the comparison between the predicted and observed values displayed in Figure 14 would also support the usage of Mendez \& Losada's formulation under weak current regime conditions. This study does not contain enough information to confirm that the Mendez \& Losada's formulation will still be suitable when current velocities are higher than $0.2 \mathrm{~m} / \mathrm{s}$ (Figure 7). However, for the waves and current conditions analyzed here, this formulation predicted the wave energy dissipation adequately.

\subsection{Bulk Drag Coefficient Formulations}

Our results revealed a fair decrease of $C_{d}$ with higher Re numbers, as it was observed in previous studies such as Anderson and Smith (2014) and Maza et al. (2015). Furthermore, emergent conditions resulted in higher $C_{d}$ values, regardless of the nondimensional hydrodynamic number analyzed ( $\mathrm{KC}$ and $\mathrm{Re}$ ). The same processes were observed in the Anderson and Smith (2014) experiments, under emergent and near-emergent conditions. These authors also stated that both Re and $\mathrm{KC}$ number relationships with $C_{d}$ did not accurately capture the emergent conditions values. Wu and Cox (2015) obtained a poor $C_{d}$ relationship when these coefficients were modeled as a function of Re, while $\mathrm{KC}$ resulted in being a significant better predictor than Re for emergent conditions. By contrast, Augustin et al. (2009) found that $C_{d}$ exhibited a stronger dependency of Re during emergent than near-emergent conditions. Furthermore, they observed that $\mathrm{KC}$ and $C_{d}$ were not well correlated during emergent conditions. Our data did not reveal stronger correlation with either Re or KC for any of those water-level conditions.

Although a significant scatter is displayed in Figure 13 when representing $C_{d}$ as a function of Re or KC, the relationships obtained might still provide information on the wave attenuation capacity of a real $S$. alterniflora field from the Chesapeake Bay, in comparison to previous studies. Anderson and Smith (2014) presented similar values as the ones reported here for a meadow built using Spartina mimics. Their study reported values of $C_{d}$ equal to 1.45 and 1.17 for Re of 1,000 and 1,500, respectively, while the $C_{d}$ values computed here were 1.53 and 1.09 for the same Re values. Wu and Cox (2015) experiments, also using mimics, reported $C_{d}$ varying from 1.6 to 2.2 ( $\left.\operatorname{Re} 1,000\right)$. These values were also in agreement with our data, although slightly larger than the $C_{d}$ obtained in our field-based experiment. Our results were also compared 
to other empirical expressions derived under storm conditions, although different vegetation species were used. For instance, large discrepancies were found when compared against the Möller et al. (2014) results. In the present study, $\mathrm{Re}=1,000$, resulted in $C_{d}$ equal to 1.5 , while Möller et al. (2014) reported a $C_{d}$ of 0.25 for similar Re values. It is important to note that more flexible saltmarsh species than Spartina, such as Elymus athericus, Puccinellia maritima, and Atriplex prostrata, were used in Möller et al.'s experiment. The biomechanical properties of these species differ significantly from the ones observed for S. alterniflora. Therefore, these discrepancies in $C_{d}$ can be attributed to the differences observed in the plant biomechanical properties as they strongly influence the wave attenuation (Bouma et al., 2010; Lara et al., 2016).

The relationship between $C_{d}$ and $h_{r}$ shown in Figure $11\left(\rho^{2}=0.60-0.77\right)$ was also noticed in previous studies such as Mendez and Losada (2004). In their study, they modified $\mathrm{KC}$ based on the $h_{r}$ and they obtained a significant improvement of the relationship between $C_{d}$ and $\mathrm{KC}$ when comparing with the ordinary $\mathrm{KC}$. Similarly, in this study, the modification of $\mathrm{KC}$ and Re numbers based on this parameter resulted in a remarkably enhancement of the representation of $C_{d}$ as a function of $\mathrm{KC}$ and Re for both cases, when separating between current directions and considering them simultaneously. Anderson and Smith (2014) also modified Re and KC by applying a factor as a function of the relative water depth. They obtained a better representation of the emergent $C_{d}$ values, although the submerged or near-emergent coefficients did not improve significantly.

\section{Coastal Engineering Considerations}

In order to support the utilization of saltmarsh ecosystems as natural or hybrid solutions (combination of natural and built infrastructure) for coastal protection, we quantitatively assessed the protection service ability of this vegetation field, in terms of wave height reduction, under a wide range of hypothetical sea conditions that can be experienced at the mid-Atlantic region of the East Coast. Furthermore, the impact of the representative $S$. alterniflora properties including stem length, stem density, and stem diameter on the wave attenuation was explored. Although the conditions assessed in this section were considerably more severe than those employed to derive our formulations, these outcomes can provide information to coastal decision makers when considering the conservation or restoration of saltmarshes as a coastal protection strategy. However, caution is needed when applying this information as, among other uncertainties, stem bending angle, flattening, folding, or breakage produced by extreme hydrodynamic conditions were not considered here, and these processes might reduce the attenuation capacity of this saltmarsh.

\subsection{Wave Attenuation Under a Comprehensive Range of Sea and Meadow Conditions}

After a successful validation of the proposed methodology, the expression derived on the previous section of this study (equation (8)) was used to compute $C_{d}$ for a comprehensive range of hypothetical sea state conditions, with water depths varying from 0.5 to $4.0 \mathrm{~m}$, wave heights up to $1.5 \mathrm{~m}$, and $T_{P}$ equal to $3,6,10$, and $10 \mathrm{~s}$. Then equations (2) and (3) were employed to estimate wave damping coefficients and ultimately, wave height reduction at $100 \mathrm{~m}$ from the marsh edge. Note that the critical breaking parameter, previously defined, was limited to 0.3 in order to only consider wave attenuation induced by the presence of the vegetation.

According to Figure 15, waves propagating under shallow water depths ( 1-m depth) were efficiently attenuated, and after $100 \mathrm{~m}$, their heights were reduced by $70 \%$, which is in accordance to the global observations reported by Narayan et al. (2016). When the water depth increases, the attenuation capacity of the saltmarsh is reduced. For instance, while a sea state with $0.5-\mathrm{m}$ wave heights and $T_{p}=3 \mathrm{~s}$ propagating over $1.5 \mathrm{~m}$ of water depths was attenuated around 50\%, similar waves travelling over 2 and $3 \mathrm{~m}$ of water depth were attenuated only 30 and $10 \%$, respectively. Also, it can be observed that, under similar water depth conditions, larger waves were more efficiently attenuated. Regarding the peak period effect on wave attenuation, Figure 15 shows that longer periods were more attenuated than shorter ones. For instance, for $2 \mathrm{~m}$ of water depth, wave heights equal to $0.5 \mathrm{~m}$ and $T_{P}$ of 3-, 6-, 10-, and 16-s waves were attenuated 29,40 , 41 , and $42 \%$, respectively. Smith et al. (2016), based on laboratory data, derived a $C_{d}$ expression and they noticed higher attenuation for waves with longer periods. However, both field and laboratory experiments have revealed contradictory results, and even conflicting trends were observed during the same experiments (Anderson \& Smith, 2014; Maza et al., 2015). These previous observations, along with our results, might 

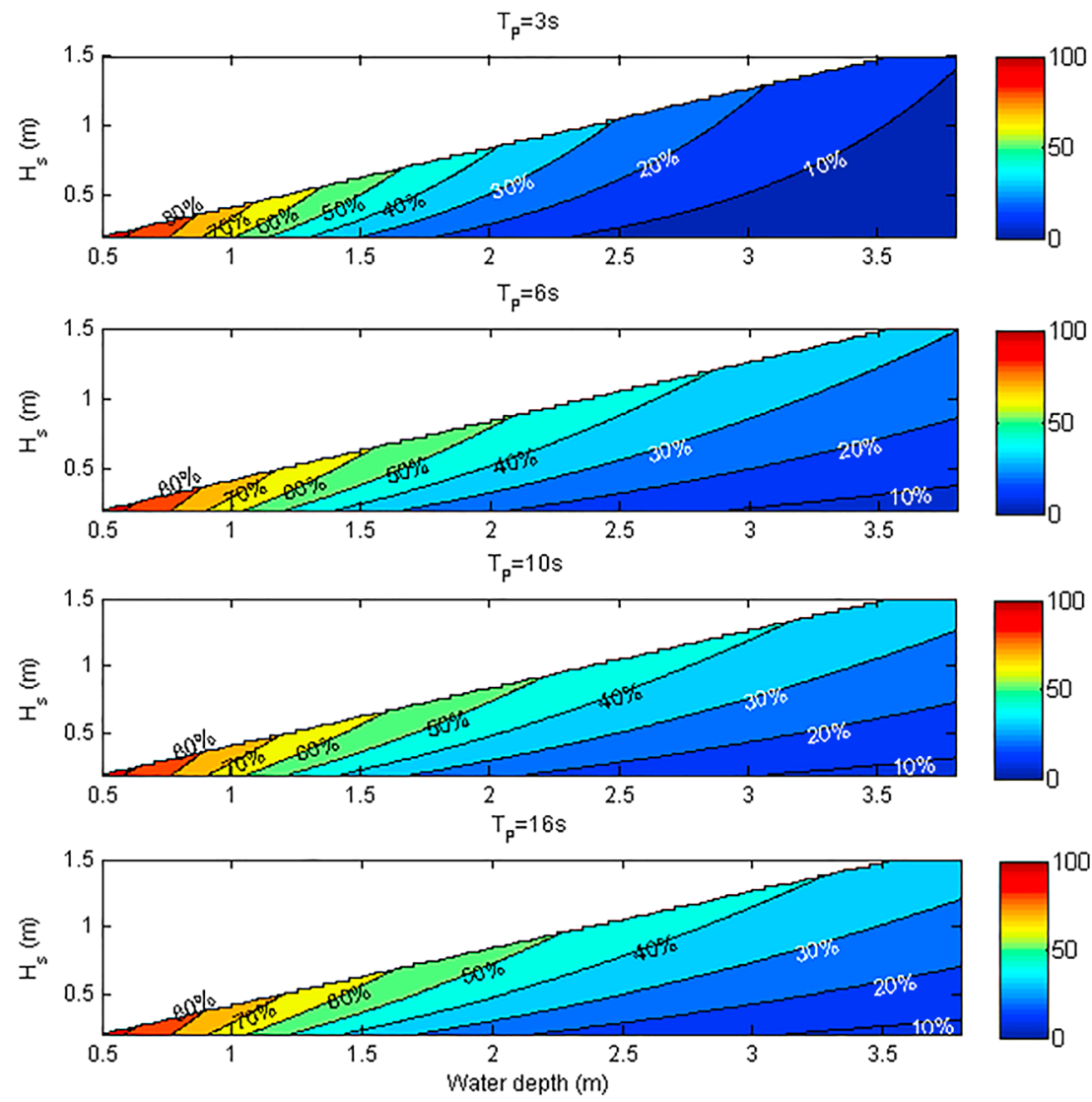

Figure 15. Wave height reduction (\%) induced by the vegetation at $100 \mathrm{~m}$ from the marsh edge as a function of water depth, significant wave height, and peak period.

Table 3

Water Depth and the Incoming $H_{S}$ and at the Marsh Edge for Each Evaluated Case and the $C_{d}$ and $\beta$ Associated

\begin{tabular}{lcccc}
\hline Case & Depth $(\mathrm{m})$ & $H_{S}(\mathrm{~m})$ & $\beta$ & $C_{d}$ \\
\hline 1 & 0.45 & 0.15 & 0.092 & 1.671 \\
2 & 0.75 & 0.30 & 0.036 & 0.694 \\
3 & 0.90 & 0.35 & 0.025 & 0.585 \\
4 & 1.05 & 0.40 & 0.019 & 0.526 \\
5 & 1.30 & 0.50 & 0.014 & 0.475 \\
6 & 1.75 & 0.70 & 0.009 & 0.439 \\
7 & 2.00 & 0.80 & 0.008 & 0.430 \\
8 & 2.40 & 0.90 & 0.006 & 0.423 \\
9 & 2.80 & 1.05 & 0.005 & 0.419 \\
10 & 3.05 & 1.15 & 0.005 & 0.417 \\
11 & 3.40 & 1.30 & 0.004 & 0.416 \\
12 & 3.80 & 1.40 & 0.004 & 0.415 \\
13 & 4.15 & 1.55 & 0.003 & 0.414 \\
\hline
\end{tabular}

indicate that peak period has a smaller effect on wave attenuation, compared to other variables, such as water depth and plant characteristics (Smith et al., 2016).

Additionally, the relative wave height evolution along a 250-m cross-shore transect was evaluated for different cases shown in Table 3 (cases 1-13) and a combination of different vegetation parameters (stem length, stem density, and stem diameter). Table 3 displays the conditions considered in these 13 cases. Water depths and wave heights of these cases were derived based on the 13 Annual Exceedance Probability values reported by the Coastal Hazard System (see Cialone et al. (2015) and NadalCaraballo et al. (2015) for further details). Cases ranged from mild conditions (case 1) to extreme conditions (case 13). The range of the vegetation parameters considered here was based on previous studies involving S. alterniflora (Glass et al., 2017; R. Jadhav \& Chen, 2012; Knutson et al., 1982). Three stem lengths $(0.4,0.6$, and $0.8 \mathrm{~m})$, three stem densities $\left(200,300\right.$, and 400 stem per $\left.\mathrm{m}^{2}\right)$, and three stem diameters $(4,5.5$, and $7 \mathrm{~mm}$ ) were tested. Figure 16 displays that cases $1-5$ were efficiently attenuated for intermediate meadow conditions $(\varnothing=5.5 \mathrm{~mm}, N=300$ stems per $\mathrm{m}^{2}$, and $l_{d}=0.6 \mathrm{~m}$ ). Wave height decays ranged from 85 to $40 \%$ within the first $50 \mathrm{~m}$, with a strong exponential decay for the cases with lower water depths. After $150 \mathrm{~m}$ inside the vegetation field, waves were slightly attenuated (less than 10\%). On the other hand, for higher water depths and the same intermediate meadow conditions, incoming wave heights of 0.8 and $1.55 \mathrm{~m}$ reported for cases 7 and 13, which were 

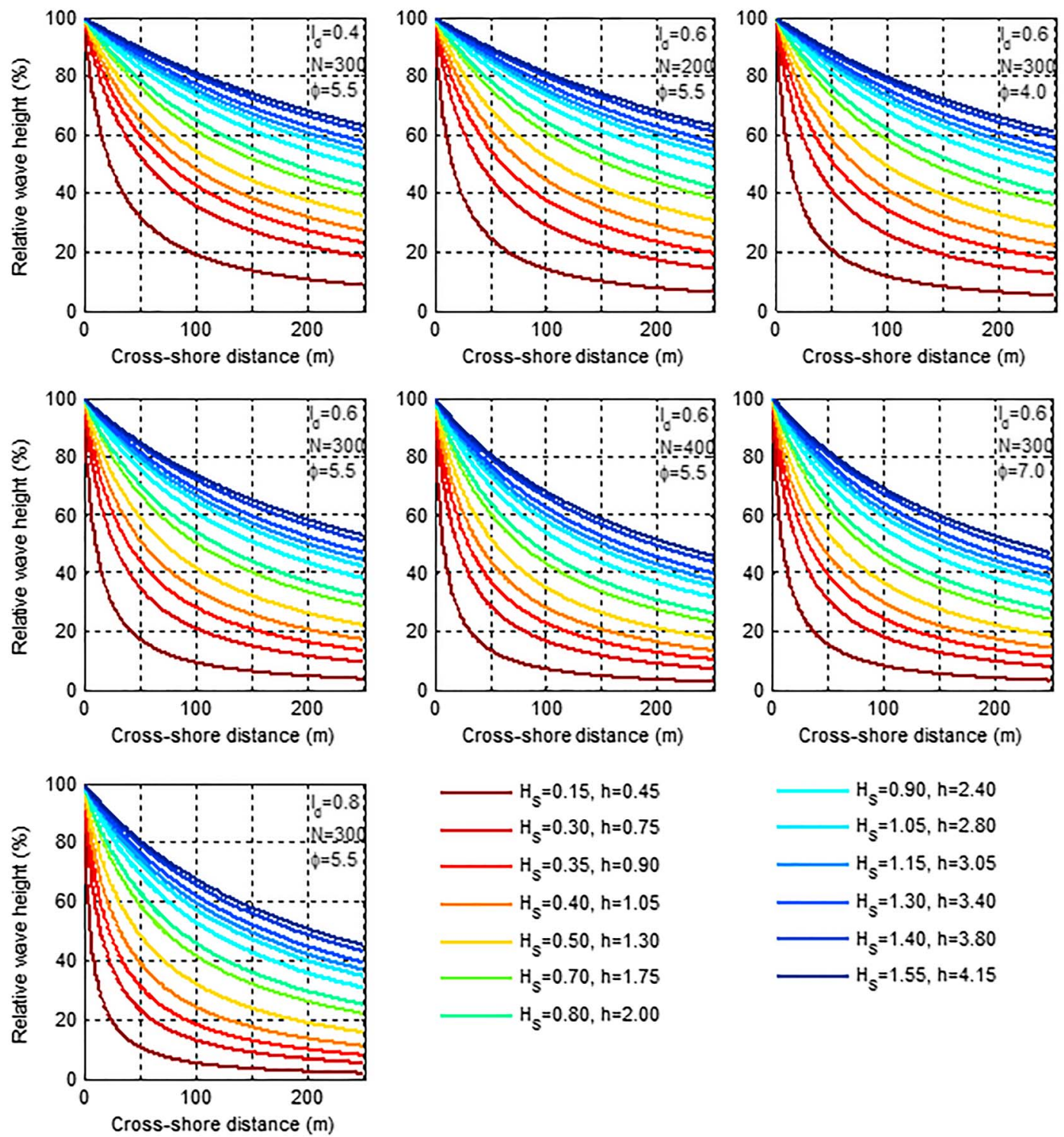

Figure 16. Relative wave height inside the vegetation field for the different cases and vegetation parameters scenarios. $H_{S}$ and $h$ units are given in m.

approximately comparable to a 100-year and 10,000 recurrence interval storm (based on the Coastal Hazard System report), were attenuated $70 \%$ and 50\%, respectively, at $250 \mathrm{~m}$ from the marsh edge.

Table 3 reports $\beta$ and $C_{d}$ associated to each case and considering intermediate meadow conditions. Models based on the wave action balance equation, such as XBeach and SWAN, rely on Mendez \& Losada's formulation to represent the physical processes within the vegetation, with only one calibration parameter required, the bulk drag coefficient (van Rooijen et al., 2015; Suzuki et al., 2012). Hence, the proper selection of this coefficient represents one the main uncertainties involved in these type of models (Vuik et al., 2016). These values might shed further light on future studies considering wave-vegetation interactions.

Regarding the influence of the vegetation characteristics, such as stem height, Figure 16 shows that with emergent conditions, the amount of energy dissipated was remarkably higher than with near-emergent conditions during the first $50 \mathrm{~m}$. However, the differences in wave dissipation induced by 0.4 (nearemergent) and 0.8 (emergent) stems were very small (10\%) after $200 \mathrm{~m}$ for cases 1 and 2 . Therefore, the influence of the stem length was weaker for longer marsh platforms. After $250 \mathrm{~m}$, emergent and near emergent conditions induced similar wave decay. When analyzing higher water depths, the attenuation induced by the vegetation decreased, as larger relative water depths resulted in lower dissipation rates. Similarly, 
waves were more attenuated with larger stems. For instance, case 11 revealed that the tallest stems reduced the wave height more than $12 \%$ than the shortest stems after $50 \mathrm{~m}$. At $200 \mathrm{~m}$, the relative wave height attenuation induced by 0.4 and 0.8 stems is 40 and $60 \%$, respectively, with a difference between both scenarios of $20 \%$. Therefore, the wave height decay differences induced by this vegetation after $200 \mathrm{~m}$ were higher in comparison to the wave decay differences at $50 \mathrm{~m}$. This indicated that with higher water depths at the marsh platform, the wave height decay at $250 \mathrm{~m}$ was sensitive to the stem length. The differences between wave height dissipation induced by the shortest and the tallest stems increased with the distance across the vegetation field (at least up to $250 \mathrm{~m}$ ).

Wave height decay sensitivity to stem density is also displayed in Figure 16. Similarly to the stem length evaluation, under near emergent conditions (cases 1 and 2), the wave height decay was very sensitive to the stem density, but only at the first section of the transect $(\sim 50 \mathrm{~m})$. At the end of the cross-shore transect, the three densities tested here provide similar wave height decay. On the other hand, the influence of the stem density on the wave attenuation was weaker for high water depths over the marsh than for shallow depths (nearemergent conditions) at the first portion of the marsh. However, the impact of the stem density on the wave attenuation was more significant after $200 \mathrm{~m}$. This stem density influence at the backside of the marsh increased with higher water depths. The wave height decay sensitivity to the stem diameter behaved similarly to the rest of vegetation parameters. Hence, the relative water depth strongly controlled the impact of the stem diameter on the wave height decay.

\section{Conclusions}

This study investigated the wave attenuation capacity of a S. alterniflora saltmarsh along a cross-shore transect at a natural preserve area of the Chesapeake Bay. Currents at seaward and over the marsh platform impacted the wave height propagation along the transect. Seaward of the marsh, lateral currents affected wave propagation leading to higher relative wave heights $\left(H_{S, 2} / h\right)$ at the marsh edge (S2) during flood than ebb tides, when total velocities were less intense. It resulted in higher wave attenuation by vegetation for higher relative incident wave heights. At the marsh platform, current directions caused that damping coefficients could be properly represented as a function of $h_{r}$ when separating between currents following waves and currents opposing waves. The relative water depth, $h_{r}$, also highly impacted the wave height decay with larger attenuation rates observed during emergent than during near-emergent conditions. Wave damping coefficient, $\beta$, exhibited a high correlation with $h_{r}$, yielding values of $\rho^{2}=0.67$ (following currents) and $\rho^{2}$ $=0.77$ (opposing currents). Moreover, damping coefficients were more sensitive to $H_{S, 2} / h$ ratios in shallower water conditions.

When analyzing following and opposing currents distinctively, the correlation of drag coefficient, $C_{d}$, as a function of Re and $h_{r}$ showed a moderate agreement, while the relationship with the KC was weaker. A $h_{r}$-based modified Re and KC significantly improved the relationship with $C_{d}$, and the agreement reached values of $\rho^{2}$ up to $0.7-0.8$. Similarly, when considering following and opposing currents together, the representation of $C_{d}$ as a function of the modified Re and KC led to correlation coefficients higher than 0.6, with KC slightly outperforming Re.

The modified Re and KC expressions along with Mendez \& Losada's formulation, derived for random waves, were used to compute significant wave heights over the marsh platform during a second storm event. Computed wave heights were compared against wave height observations measured within the vegetation meadow yielding values of root-mean-square error of $0.013-0.014 \mathrm{~m}$. The worst agreement was found for the largest waves $(>0.20 \mathrm{~m})$ leading to an overestimation up to $18 \%$. The performance of the proposed formulations corroborated the existing theory applied on this experiment.

The proposed $C_{d}$ formulations were applied to a large range of sea states and vegetation characteristics to provide some empirically based information about the attenuation capacity of these ecosystems considering a comprehensive range of hypothetical sea conditions and S. alterniflora characteristics. When exploring the effects of vegetation parameters on the wave height decay, larger stem length, density, and diameter induced higher wave attenuation. Nevertheless, the relative water depth strongly controlled the impact of these parameters on the wave height decay. For near-emergent conditions, wave attenuation was very sensitive to changes in these vegetation parameters during the first $50 \mathrm{~m}$, while this sensitivity decreased further 
inland in the marsh. For higher water depths, changes in these vegetation parameters had larger impact on wave attenuation at locations further inland than at the marsh edge.

This study demonstrated that considering spatial scales of the order of 200-400 m, such as areas commonly found in the Chesapeake Bay and worldwide, saltmarshes are a viable option to be considered into coastal defense schemes, even for severe storm conditions, as those studied here. However, further studies evaluating the ability of the derived formulations to represent wave attenuation by vegetation should be carried out under different hydrodynamics and vegetation conditions. Those studies would help to provide additional support to promote coastal wetlands restoration and preservation and ultimately, their inclusion into coastal defense schemes.

\section{Acknowledgments}

This material is based upon work supported by the National Fish and Wildlife Foundation and the U.S. Department of the Interior under grant 43932. The views and conclusions contained in this document are those of the authors and should not be interpreted as representing the opinions or policies of the U.S. Government or the National Fish and Wildlife Foundation and its funding sources. Mention of trade names or commercial products does not constitute their endorsement by the U.S. Government, or the National Fish and Wildlife Foundation or its funding sources. This material is also based upon work supported by the National Science Foundation under grant SES-1331399. Any opinions, findings, and conclusions or recommendations expressed in this material are those of the authors and do not necessarily reflect the views of the National Science Foundation. This research was also supported in part by the Thomas F. and Kate Miller Jeffress Memorial Trust, Bank of America, Trustee. Additionally, the authors really appreciate all the support from their partners at the DCR/VA and the USFWS that without their support, this work would not have been possible. The authors are also extremely grateful to all the hard work during the field campaign data collections from Mithun Deb, Seth Lawler, Lindsey Kellar, Jana Haddad, Eléonore Paquier, and Beverly Lanza. Moreover, the authors highly appreciate the supporting efforts carried out by Tyler Miesse during the review process. M. Maza, J.L. Lara, and I.J. Losada are indebted to the Spanish Ministry of Economy and Competitiveness for the funding provided in the RETOS INVESTIGACION 2014 (grant BIA2014-59718-R) grant program. Readers can access the data used in this study through this website: http:// www.hydroshare.org/resource/ 51346939a66a45e5b7e4a33b48645a6c. Lab, F. M. F. H. (2019). Storm Surge Eastern Shore of Virginia National Wildlife Refuge, HydroShare.

\section{References}

Anderson, M. E., \& Smith, J. M. (2014). Wave attenuation by flexible, idealized salt marsh vegetation. Coastal Engineering, 83, 82-92. https://doi.org/10.1016/j.coastaleng.2013.10.004

Augustin, L. N., Irish, J. L., \& Lynett, P. (2009). Laboratory and numerical studies of wave damping by emergent and near-emergent wetland vegetation. Coastal Engineering, 56(3), 332-340. https://doi.org/10.1016/j.coastaleng.2008.09.004

Barbier, E. B., Hacker, S. D., Kennedy, C., Koch, E. W., Stier, A. C., \& Silliman, B. R. (2011). The value of estuarine and coastal ecosystem services. Ecological Monographs, 81(2), 169-193. https://doi.org/10.1890/10-1510.1

Bouma, T., de Vries, M., \& Herman, P. (2010). Comparing ecosystem engineering efficiency of 2 plant species with contrasting growth strategies. Ecology, 91(9), 2696-2696. https://doi.org/10.1890/09-0690

Bouma, T. J., de Vries, M. B., Low, E., Peralta, G., Tánczos, I. C., van de Koppel, J., \& Herman, P. M. J. (2005). Trade-offs related to ecosystem engineering: A case study on stiffness of emerging macrophytes. Ecology, 86(8), 2187-2199. https://doi.org/10.1890/ $04-1588$

Bradley, K., \& Houser, C. (2009). Relative velocity of seagrass blades: Implications for wave attenuation in low-energy environments. Journal of Geophysical Research, 114, F01004. https://doi.org/10.1029/2007JF000951

Castagno, K. A., Jiménez-Robles, A. M., Donnelly, J. P., Wiberg, P. L., Fenster, M. S., \& Fagherazzi, S. (2018). Intense storms increase the stability of tidal bays. Geophysical Research Letters, 5491-5500. https://doi.org/10.1029/2018GL078208

Chen, Y., Li, Y., Cai, T., Thompson, C., \& Li, Y. (2016). A comparison of biohydrodynamic interaction within mangrove and saltmarsh boundaries. Earth Surface Processes and Landforms, 41(13), 1967-1979. https://doi.org/10.1002/esp.3964

Cialone, M. A., Massey, T. C., Anderson, M. E., Grzegorzewski, A. S., Jensen, R. E., Cialone, A., et al. (2015). North Atlantic Coast Comprehensive Study (NACCS) Coastal storm model simulations: Waves and water levels, (January). Retrieved from http://oai.dtic. mil/oai/oai?verb=getRecord\&metadataPrefix=html\&identifier=ADA621343

Costanza, R., Pérez-Maqueo, O., Martinez, M. L., Sutton, P., Anderson, S. J., \& Mulder, K. (2008). The value of coastal wetlands for hurricane protection. Ambio: A Journal of the Human Environment, 37(4), 241-248. https://doi.org/10.1579/0044-7447(2008)37[241: TVOCWF]2.0.CO;2

D'Alpaos, A., Mudd, S. M., \& Carniello, L. (2011). Dynamic response of marshes to perturbations in suspended sediment concentrations and rates of relative sea level rise. Journal of Geophysical Research, 116, F04020. https://doi.org/10.1029/2011JF002093

Donatelli, C., Kamal Ganju, N., Fagherazzi, S., \& Leonardi, N. (2018). Seagrasses impact sediments exchange between tidal glats andthe sediment budget of shallow bays. Geophysical Research Letters, 45, 4933-4943. https://doi.org/10.1029/2018GL078056

Garzon, J. L., Miesse, T., \& Ferreira, C. M. (2019). Field-based numerical model investigation of wave propagation across marshes in the Chesapeake Bay under storm conditions. Coastal Engineering, 146, 32-46. https://doi.org/10.1016/j.coastaleng.2018.11.001

Gaylord, B., Denny, M. W., \& Koehl, M. A. R. (2003). Modulation of wave forces on kelp canopies by alongshore currents. Limnology and Oceanography, 48(2), 860-871. https://doi.org/10.4319/lo.2003.48.2.0860

Glass, E. M., Garzon, J. L., Lawler, S., Paquier, E., \& Ferreira, C. M. (2017). Potential of marshes to attenuate storm surge water level in the Chesapeake Bay. Limnology and Oceanography, 63(2), 951-967. https://doi.org/10.1002/lno.10682

Hu, Z., Suzuki, T., Zitman, T., Uittewaal, W., \& Stive, M. (2014). Laboratory study on wave dissipation by vegetation in combined currentwave flow. Coastal Engineering, 88, 131-142. https://doi.org/10.1016/j.coastaleng.2014.02.009

Jackson, D., Mason, C. F., \& Long, S. P. (1985). Macro-invertebrate populations and production on a salt-marsh in east England dominated by Spartina anglica. Oecologia, 65(3), 406-411. https://doi.org/10.1007/BF00378916

Jadhav, R., \& Chen, Q. (2012). Field investigation of wave dissipation over salt marsh vegetation during tropical cyclone. Coastal Engineering Proceedings, 1, 1-11. Retrieved from http://journals.tdl.org/icce/index.php/icce/article/view/6575

Jadhav, R. S., Chen, Q., \& Smith, J. M. (2013). Spectral distribution of wave energy dissipation by salt marsh vegetation. Coastal Engineering, 77, 99-107. https://doi.org/10.1016/j.coastaleng.2013.02.013

Kirwan, M. L., Guntenspergen, G. R., D'Alpaos, A., Morris, J. T., Mudd, S. M., \& Temmerman, S. (2010). Limits on the adaptability of coastal marshes to rising sea level. Geophysical Research Letters, 37, L23401. https://doi.org/10.1029/2010GL045489

Knutson, P. L., Brochu, R. A., Seelig, W. N., \& Inskeep, M. (1982). Wave damping in Spartina alterniflora marshes. Wetlands, 2(1), 87-104. https://doi.org/10.1007/BF03160548

Kobayashi, N., Raichle, A. W., \& Asano, T. (1993). Wave attenuation by vegetation. Journal of Waterway Port Coastal and Ocean Engineering, 119(1), 30-48. https://doi.org/10.1061/(ASCE)0733-950X(1993)119:1(30)

Lara, J. L., Maza, M., Ondiviela, B., Trinogga, J., Losada, I. J., Bouma, T. J., \& Gordejuela, N. (2016). Large-scale 3-D experiments of wave and current interaction with real vegetation. Part 1: Guidelines for physical modeling. Coastal Engineering, 107, 70-83. https://doi.org/ 10.1016/j.coastaleng.2015.09.012

Li, C. W., \& Yan, K. (2007). Numerical investigation of wave-current-vegetation interaction. Journal of Hydraulic Engineering, 133(7), 794-803. https://doi.org/10.1061/(ASCE)0733-9429(2007)133:7(794)

Liu, P. L.-F. (1983). Wave-current interactions on a slowly varying topograph. Journal of Geophysical Research, 88(C7), 4421-4426. https:// doi.org/10.1029/JC088iC07p04421

Losada, I. J., Maza, M., \& Lara, J. L. (2016). A new formulation for vegetation-induced damping under combined waves and currents. Coastal Engineering, 107, 1-13. https://doi.org/10.1016/j.coastaleng.2015.09.011 
Maza, M., Lara, J. L., Losada, I. J., Ondiviela, B., Trinogga, J., \& Bouma, T. J. (2015). Large-scale 3-D experiments of wave and current interaction with real vegetation. Part 2: Experimental analysis. Coastal Engineering, 106, 73-86. https://doi.org/10.1016/j. coastaleng.2015.09.010

Mendez, F. J., \& Losada, I. J. (2004). An empirical model to estimate the propagation of random breaking and nonbreaking waves over vegetation fields. Coastal Engineering, 51(2), 103-118. https://doi.org/10.1016/j.coastaleng.2003.11.003

Möller, I. (2006). Quantifying saltmarsh vegetation and its effect on wave height dissipation: Results from a UK East coast saltmarsh. Estuarine, Coastal and Shelf Science, 69(3-4), 337-351. https://doi.org/10.1016/j.ecss.2006.05.003

Möller, I., Kudella, M., Rupprecht, F., Spencer, T., Paul, M., van Wesenbeeck, B. K., et al. (2014). Wave attenuation over coastal salt marshes under storm surge conditions. Nature Geoscience, 7(10), 727-731. https://doi.org/10.1038/ngeo2251

Möller, I., \& Spencer, T. (2002). Wave dissipation over macro-tidal saltmarshes: Effects of marsh edge typology and vegetation change. Journal of Coastal Research, 36(36), 506-521. https://doi.org/10.2112/1551-5036-36.sp1.506

Mudd, S. M., D'Alpaos, A., \& Morris, J. T. (2010). How does vegetation affect sedimentation on tidal marshes? Investigating particle capture and hydrodynamic controls on biologically mediated sedimentation. Journal of Geophysical Research, 115, F03029. https://doi.org/ 10.1029/2009JF001566

Nadal-Caraballo, N. C., Melby, J. A., Gonzalez, V. M., \& Cox, A. T. (2015). Coastal storm hazards from Virginia to Maine Coastal and Hydraulics Laboratory, (November).

Narayan, S., Beck, M. W., Reguero, B. G., Losada, I. J., van Wesenbeeck, B., Pontee, N., et al. (2016). The effectiveness, costs and coastal protection benefits of natural and nature-based defences. PLOS ONE, 11(5), e0154735. https://doi.org/10.1371/journal.pone.0154735

Nepf, H. M. (2004). Vegetated flow dynamics introduction: Scales of morphology and flow in a tidal marsh. Coastal and Estuarine Studies, 59, 137-163.

Ozeren, Y., Wren, D. G., \& Wu, W. (2014). Experimental investigation of wave attenuation through model and live vegetation. Journal of Waterway, Port, Coastal, and Ocean Engineering, 140(5), 1-12. https://doi.org/10.1061/(ASCE)WW.1943-5460.0000251

Paquier, A.-E., Haddad, J., Lawler, S., \& Ferreira, C. M. (2016). Quantification of the attenuation of storm surge components by a coastal wetland of the US Mid Atlantic. Estuaries and Coasts, 40(4), 930-946. https://doi.org/10.1007/s12237-016-0190-1

Paul, M., \& Amos, C. L. (2011). Spatial and seasonal variation in wave attenuation over Zostera noltii. Journal of Geophysical Research, 116 , C08019. https://doi.org/10.1029/2010JC006797

Paul, M., Bouma, T., \& Amos, C. (2012). Wave attenuation by submerged vegetation: Combining the effect of organism traits and tidal current. Marine Ecology Progress Series, 444, 31-41. https://doi.org/10.3354/meps09489

Paul, M., Rupprecht, F., Möller, I., Bouma, T. J., Spencer, T., Kudella, M., et al. (2016). Plant stiffness and biomass as drivers for drag forces under extreme wave loading: A flume study on mimics. Coastal Engineering, 117, 70-78. https://doi.org/10.1016/j. coastaleng.2016.07.004

Raubenheimer, B., Guza, R. T., \& Elgar, S. (2001). Field observations of wave-driven setdown and setup. Journal of Geophysical Research, 106(C3), 4629-4638. https://doi.org/10.1029/2000JC000572

Resio, D. T., \& Westerink, J. J. (2008). Modeling the physics of storm surges. Physics Today, 61(9), 33-38. https://doi.org/10.1063/1.2982120

Rupprecht, F., Möller, I., Paul, M., Kudella, M., Spencer, T., van Wesenbeeck, B. K., et al. (2017). Vegetation-wave interactions in salt marshes under storm surge conditions. Ecological Engineering, 100, 301-315. https://doi.org/10.1016/j.ecoleng.2016.12.030

Smith, J. M., Bryant, M. A., \& Wamsley, T. V. (2016). Wetland buffers: Numerical modeling of wave dissipation by vegetation. Earth Surface Processes and Landforms, 41(6), 847-854. https://doi.org/10.1002/esp.3904

Stevenson, J. C., Kearney, M. S., \& Pendleton, E. C. (1985). Sedimentation and erosion in a Chesapeake Bay brackish marsh system. Marine Geology, 67, 213-235. https://doi.org/10.1016/0025-3227(85)90093-3

Sutton-Grier, A. E., Wowk, K., \& Bamford, H. (2015). Future of our coasts: The potential for natural and hybrid infrastructure to enhance the resilience of our coastal communities, economies and ecosystems. Environmental Science \& Policy, 51, 137-148. https://doi.org/ 10.1016/j.envsci.2015.04.006

Suzuki, T., Zijlema, M., Burger, B., Meijer, M. C., \& Narayan, S. (2012). Wave dissipation by vegetation with layer schematization in SWAN. Coastal Engineering, 59(1), 64-71. https://doi.org/10.1016/j.coastaleng.2011.07.006

Temmerman, S., Meire, P., Bouma, T. J., Herman, P. M. J., Ysebaert, T., \& de Vriend, H. J. (2013). Ecosystem-based coastal defence in the face of global change. Nature, 504(7478), 79-83. https://doi.org/10.1038/nature12859

Thomas, G. P., \& Klopman, G. (1997). Wave-current interactions in the near shore region. International Series on Advances in Fluid Mechanics, 10, 255-319.

Thornton, E. B., \& Guza, R. T. (1982). Energy saturation and phase speeds measured on a natural beach. Journal of Geophysical Research, 87(C12), 9499-9508. https://doi.org/10.1029/JC087iC12p09499

van Rooijen, A. A., van thiel de Vries, J. S. M., McCall, R. T., van Dongeren, A. R., Roelvink, J. A., \& Reniers, A. J. H. M. (2015). Modeling of wave attenuation by vegetation with XBeach. E-Proceedings of the 36th IAHR World Congress, 7.

Vuik, V., Jonkman, S. N., Borsje, B. W., \& Suzuki, T. (2016). Nature-based flood protection: The efficiency of vegetated foreshores for reducing wave loads on coastal dikes. Coastal Engineering, 116, 42-56. https://doi.org/10.1016/j.coastaleng.2016.06.001

Woodroffe, C. D., Rogers, K., McKee, K. L., Lovelock, C. E., Mendelssohn, I. A., \& Saintilan, N. (2016). Mangrove sedimentation and response to relative sea-level rise. Annual Review of Marine Science, 8(1), 243-266. https://doi.org/10.1146/annurev-marine-122414034025

Wu, W., \& Cox, D. T. (2015). Effects of wave steepness and relative water depth on wave attenuation by emergent vegetation. Estuarine, Coastal and Shelf Science, 164, 443-450. https://doi.org/10.1016/j.ecss.2015.08.009

Xiong, Y., \& Berger, C. R. (2010). Chesapeake Bay tidal characteristics. Journal of Water Resource and Protection, 2(7), 619-628. https://doi. org/10.4236/jwarp.2010.27071

Yang, S. L., Shi, B. W., Bouma, T. J., Ysebaert, T., \& Luo, X. X. (2012). Wave attenuation at a salt marsh margin: A case study of an exposed coast on the Yangtze estuary. Estuaries and Coasts, 35(1), 169-182. https://doi.org/10.1007/s12237-011-9424-4

Ysebaert, T., Yang, S. L., Zhang, L., He, Q., Bouma, T. J., \& Herman, P. M. J. (2011). Wave attenuation by two contrasting ecosystem engineering salt marsh macrophytes in the intertidal pioneer zone. Wetlands, 31(6), 1043-1054. https://doi.org/10.1007/s13157-011$0240-1$ 